\title{
EVALUACIÓN DEL GRADO DE DAÑO EN LA CIUDAD DE PASTO (COLOMBIA) A CAUSA DE SISMOS HISTÓRICOS
}

\section{ASSESSMENT OF DAMAGE GRADE IN THE CITY OF PASTO (COLOMBIA) DUE TO HISTORICAL EARTHOUAKES}

Ana Milena Sarabia ${ }^{1}$, Hernán Guillermo Cifuentes ${ }^{2}$

*Email de correspondencia: asarabia@sgc.gov.co

Recibido: 8/08/2017

Aceptado: 23/02/2018

Publicado en línea: 20/04/2018

Citación: Sarabia, A. y Cifuentes, H. (2018). Evaluación del grado de daño en la ciudad de Pasto (Colombia) a causa de sismos históricos. Boletín Geológico, 44, 133-152.

Nota del autor: este artículo está basado en la investigación llevada a cabo por los autores en el marco del proyecto "Ampliación del conocimiento geológico y de potencial de recursos del subsuelo de la Nación" del Servicio Geológico Colombiano en el año 2013.

\section{RES U M E N}

La ciudad de San Juan de Pasto, capital del departamento de Nariño, se encuentra localizada en una zona de amenaza sísmica alta, según el Reglamento Colombiano de Construcción Sismo Resistente, $\mathrm{y}$ ha sido estremecida por varios sismos a lo largo de su historia, asociados en su mayoría a importantes fuentes sismogénicas, como lo son los sistemas de fallas de Algeciras, Romeral, Afiladores y la zona de subducción.

Se realizó la revisión de los sismos que históricamente han afectado de forma significativa (intensidad $\geq 7$ en la escala EMS-98) a la ciudad de San Juan de Pasto, con el fin de contextualizar, clasificar y evidenciar daños recurrentes, lo cual, junto a otras variables que no se incluyen en este trabajo (condiciones del suelo, topografía, etc.), es útil para dar una aproximación de efectos locales en la ciudad.

Los siguientes fueron los eventos sísmicos seleccionados: 20 de enero de 1834, 26 de octubre de 1935 y 14 de julio de 1947, los cuales averiaron considerablemente las construcciones de la ciudad. Para cada caso se analizó el tipo de construcción averiada, su vulnerabilidad y grado de daño, teniendo en cuenta el contexto histórico de cada época. Estos datos se georreferenciaron sobre el plano de la ciudad, y se observó que existen áreas en común que han sido afectadas por todos los eventos sísmicos. Palabras clave: sismicidad histórica, sismo, San Juan de Pasto, intensidad, escala de intensidad EMS-98, daños, efectos.

M. Sc. en Tecnologías de la Información Geográfica. Servicio Geológico Colombiano.

2 M. Sc. en Tecnologías de la Información Geográfica. Servicio Geológico Colombiano. 


\begin{abstract}
A B S T R A C T
San Juan de Pasto, capital of the Department of Nariño (Colombia), is located in a high seismic hazard region, according to the Regulations for Earthquake Resistant Design of Buildings. The city has been affected by several earthquakes throughout its history associated with the main seismotectonic sources in the country such as the Algeciras, Romeral, and Afiladores fault systems and the subduction zone.

A review of the historical earthquakes that have significantly affected (intensity $\geq 7$ on the EMS98) San Juan de Pasto city was carried out to contextualize, classify and evidence recurrent damage, which provides an approach to determine possible site effects in the city. There are other issues that also influence the site effects such as the soil condition and topography of the area, but these are not considered in this study.

The earthquakes selected were on January 20,1834, October 26, 1935, and July 14, 1947, which significantly damaged many structures in the city. For every case, the type of affected structure, its constructive vulnerability and the degree of damage were analyzed, taking into account the historical context of each period. These data were georeferenced on the city map, and it was observed that there are common areas that have been affected by all the seismic events.
\end{abstract}

Key words: historical seismicity, earthquake, San Juan de Pasto, intensity, European Macroseismic Scale - 1998, effects, damages.

\section{INTRODUCCIÓN}

La ciudad de San Juan de Pasto - en adelante, Pasto-, fundada hace 481 años, tomando como referencia 1537 (Cerón y Ramos, 1997), ha sido afectada en repetidas ocasiones por algunos sismos de carácter destructivo que dejaron huella en el desarrollo urbano de la ciudad y que quedaron plasmados en la literatura y documentos de diferentes épocas. Al realizar el estudio de estos eventos se ha observado que existen edificaciones y zonas que han presentado daños similares, lo cual se podría relacionar con la vulnerabilidad constructiva, pero también con efectos locales.

Respecto a los efectos locales, Altez y Laffaille (2006) dicen:

En el estudio de los sismos históricos generalmente se ha desatendido el hecho de que los grandes terremotos no producen daños de forma homogénea en las ciudades. Esta heterogeneidad de los efectos es el resultado de las propias diferencias entre las localidades (condiciones de sitio), regiones (morfología general), desarrollos constructivos (condiciones históricas y sociales de los materiales y tipos de construcción utilizados) y las relaciones culturales con el medio ambiente, lo cual significa una heterogeneidad fun- damental en las condiciones locales e infraestructurales que enfrentan a los terremotos.

Según lo anterior, y en lo que compete a este estudio, se busca analizar el tipo y grado de daño que han causado los sismos significativos en las edificaciones de la ciudad de Pasto a lo largo de su historia y georreferenciarlos en un plano, con el fin de visualizar zonas que presenten daños repetitivos. Igualmente, es importante verificar evidencias de efectos en la naturaleza desencadenados por los sismos, como deslizamientos, grietas en el terreno y licuación, entre otros.

Este análisis se realiza como parte del estudio de los efectos locales en la ciudad, y debe complementarse y cotejarse con la investigación de las condiciones geológicas y geotécnicas del área, la topografía, etc.

Para seleccionar los eventos sísmicos significativos en Pasto se realizó una "Consulta por sitio" al Sistema de Información de Sismicidad Histórica de Colombia (en adelante SISHC), disponible en línea (http://sish. sgc.gov.co/visor/). En él se encuentra almacenada la información histórica, macrosísmica y sismológica de los grandes sismos que han ocurrido en el país, teniendo en cuenta sus efectos, los documentos primarios y secundarios relacionados, la evaluación de intensidades dada 
por diferentes autores e imágenes, entre otros elementos. A partir del resultado obtenido se eligieron los eventos que han tenido intensidad $\geq 7$, ya que, según la escala EMS-98 (European Macroseismic Scale, 1998), a partir de ese grado de intensidad se presentan daños estructurales como grandes grietas en muros y caída de tejas en construcciones altamente vulnerables, como lo son las de mampostería no estructural o sin refuerzo.

Para evaluar los daños de los sismos se utilizaron los criterios de la escala de intensidad EMS-98, que considera el tipo de construcción — sus materiales y estructura-, su vulnerabilidad y el grado de daño.

\section{Metodolocía}

El listado de los sismos que, según el SISHC, han sido sentidos de forma intensa en Pasto se presenta en la tabla 1. Los parámetros sismológicos de los eventos ocurridos antes de 1950, con excepción del sismo de 1906, se evaluaron utilizando la ecuación de atenuación de Gómez et al. (2016). De esa tabla se seleccionaron los eventos que tuvieron valor de intensidad mayor o igual a 7 en la ciudad, que son los del 20 de enero de 1834, 26 de octubre de 1935 y 14 de julio de 1947. El mapa de intensidades de estos eventos se presenta en las figuras 1,2 y 3 , respectivamente, en las cuales se representa el valor de intensidad por sitio y los efectos en la naturaleza como deslizamientos y agrietamientos del terreno.

Tabla 1. Sismos sentidos en la ciudad de Pasto

\begin{tabular}{|c|c|c|c|c|c|c|c|c|c|}
\hline Fecha & Hora local* & Lat. & Long. & Mag. & Tipo mag. & Prof. km & Int. máx. & Int. Pasto & Sitio relacionado \\
\hline $1827-11-16$ & $18: 00$ & 2,06 & $-75,7$ & 7,1 & Mw & Sup. & 10 & 6 & Altamira (Huila) \\
\hline $1834-01-20$ & 7:00 & 1,2 & $-77,1$ & 6,7 & Mw & Sup. & 9 & 8 & Santiago (Putumayo) \\
\hline 1906-01-31 & $10: 36$ & 1,5 & -80 & 8,4 & Mw & Sup. & 10 & 6 & Costa pacífica \\
\hline $1935-08-07$ & 04:00 & 1,06 & $-77,35$ & 6,1 & Mw & Sup. & 8 & 6 & Tangua (Nariño) \\
\hline $1935-10-26$ & $20: 15$ & 1,1 & $-77,5$ & 5,9 & Mw & Sup. & 8 & 7 & Imués (Nariño) \\
\hline 1936-01-09 & $23: 30$ & 1,1 & $-77,6$ & 5,6 & Mw & Sup. & 7 & 5 & Túquerres (Nariño) \\
\hline $1936-07-17$ & $12: 30$ & 1,1 & $-77,6$ & 6,3 & Mw & Sup. & 8 & 5 & Túquerres (Nariño) \\
\hline 1938-02-04 & $21: 23$ & 5,61 & $-75,45$ & 7,0 & Ms & 128 & 8 & 5 & Eje cafetero \\
\hline $1947-07-14$ & $02: 00$ & 1,2 & $-77,3$ & 6,1 & Mw & Sup. & 8 & 8 & Pasto (Nariño) \\
\hline $1953-12-22$ & $23: 45$ & 1,1 & $-77,6$ & 5,8 & Mw & Sup. & 8 & 5 & Guaitarilla (Nariño) \\
\hline 1958-01-19 & 09:07 & 1,37 & $-79,34$ & 7,6 & Mw & 35 & 8 & 5 & Esmeraldas \\
\hline 1967-02-09 & $10: 24$ & 2,93 & $-74,83$ & 7,0 & Mw & 36 & 10 & 5 & Colombia (Huila) \\
\hline $1979-12-12$ & $02: 59$ & 1,6 & $-79,36$ & 8,1 & Mw & 25 & 10 & 6 & Costa Pacífica \\
\hline 1995-03-04 & $18: 23$ & 1,25 & $-77,26$ & 5,0 & ML & Sup. & 6 & 6 & Pasto (Nariño) \\
\hline
\end{tabular}

* $\quad$ Para hora UTC, sumar 5 horas. Lat.: latitud; Long.: longitud; Mag.: magnitud; Tipo mag.: tipo de magnitud; Mw: magnitud momento; Ms: magnitud de ondas superficiales; Ml: magnitud local; Prof.: profundidad; Sup.: Superficial $(<50 \mathrm{~km})$; Int. máx.: intensidad máxima del sismo (EMS-98); Int. Pasto: intensidad en la ciudad de Pasto (EMS-98); Sitio relacionado: región más afectada por el sismo.

Fuente: Sistema de Información de Sismicidad Histórica de Colombia, (http://sish.sgc.gov.co/visor/) 


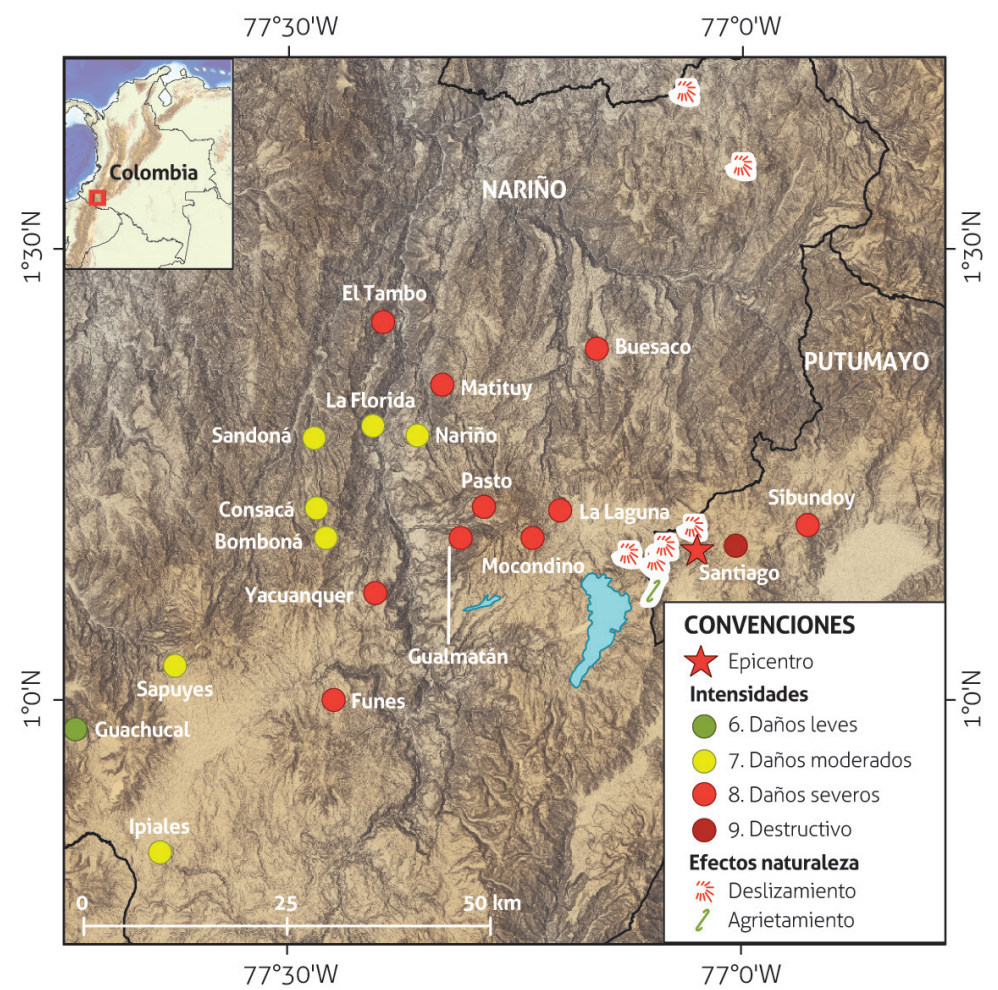

Figura 1. Mapa de intensidades del sismo del 20 de enero de 1834 Fuente: Sarabia et al. (2006)

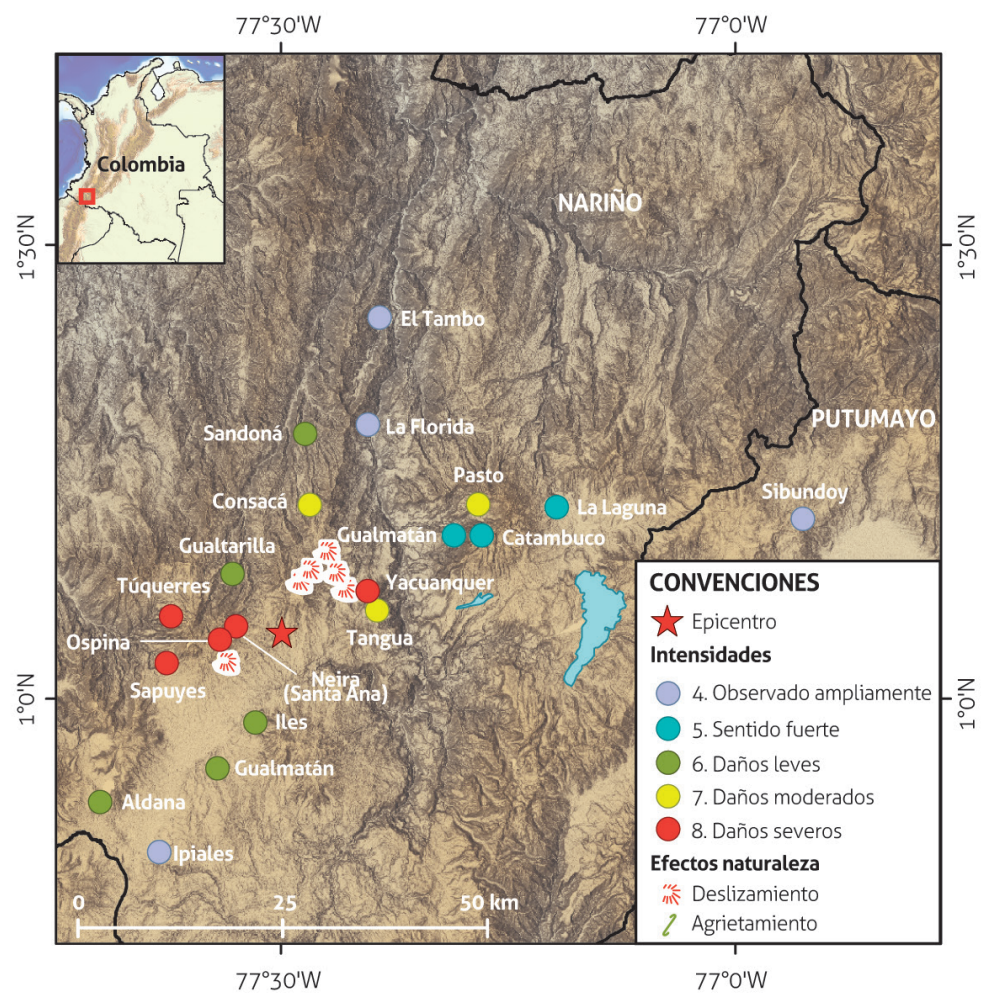

Figura 2. Mapa de intensidades del sismo del 26 de octubre de 1935 Fuente: Sarabia y Cifuentes (2010) 


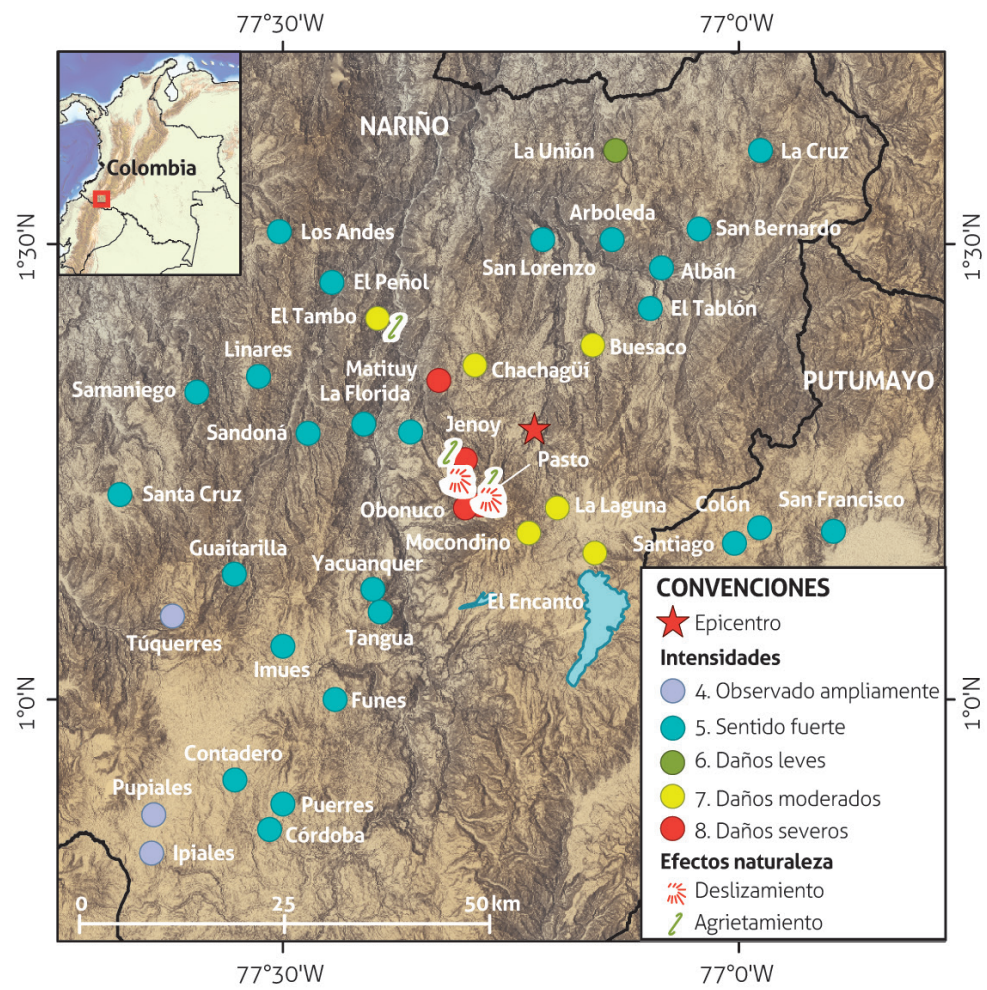

Figura 3. Mapa de intensidades del sismo del 14 de julio de 1947 Fuente: Cifuentes y Sarabia (2007)

Para recabar información de las dos épocas de ocurrencia de los sismos (inicios del siglo XIX y mediados del siglo XX) se consultaron documentos relacionados con la configuración espacial y urbana de Pasto, así como los planos con los predios existentes con el fin de conocer cómo era la ciudad y contextualizar los efectos presentados en esa área. Se georreferenciaron las edificaciones afectadas y se buscó información relacionada con el año de construcción y los materiales empleados en las mismas.

Algunas edificaciones fueron averiadas por los tres eventos analizados, por lo cual, como paso inicial, se elaboró la tabla que se encuentra en el anexo A, en la que se consignó el nombre de la edificación, el año aproximado de construcción, la dirección según la nomenclatura actual y el sismo que causó el daño, con el propósito de no duplicar información en el análisis de daños de cada evento.

Posteriormente se definió el tipo de estructura afectado, su vulnerabilidad, y se asignó el grado de daño según la escala EMS-98. Esta escala diferencia cuatro tipos de estructura: mampostería, concreto reforzado, acero y madera; y las clases de vulnerabilidad, que son seis: A, B, C, D, E y F, siendo A la clase que define el tipo de estructura más vulnerable, y F, la de menor vulnerabilidad (tabla 2). 
Tabla 2. Tipo de estructura y vulnerabilidad según la escala EMS-98

\begin{tabular}{|c|c|c|c|c|c|c|c|}
\hline & \multirow{2}{*}{ Tipo de estructura } & \multicolumn{6}{|c|}{ Clase de vulnerabilidad } \\
\hline & & A & B & C & $D$ & E & $F$ \\
\hline \multirow{7}{*}{ Mampostería } & Piedra suelta o canto rodado & $\bigcirc$ & & & & & \\
\hline & Adobe (ladrillo crudo), tapia pisada & $\mathrm{O}$ & & & & & \\
\hline & Roca simple & & & & & & \\
\hline & Roca masiva & & & & & & \\
\hline & Unidades de roca manufacturada & & & & & & \\
\hline & Ladrillo no reforzado, pisos de concreto reforzado & & & & & & \\
\hline & Reforzada o confinada & & & & & & \\
\hline \multirow{6}{*}{ Concreto reforzado } & Estructura sin diseño sismorresistente (DSR) & & & & & & \\
\hline & Estructura con nivel medio de DSR & & & & & & \\
\hline & Estructura con nivel alto de DSR & & & & & & \\
\hline & Muros $\sin$ DSR & & & & & & \\
\hline & Muros con nivel medio de DSR & & & & & & \\
\hline & Muros con nivel alto de DSR & & & & & & \\
\hline Acero & Estructuras de acero & & & & & -0 & \\
\hline Madera & Estructuras de madera & & & & & & \\
\hline
\end{tabular}

O Clase de vulnerabilidad más probable, __ Rango probable, ----- Rango de casos menos probables Fuente: Grunthal (2009)

Respecto al grado de daño, la escala describe los efectos que pueden ocurrir en estructuras de mampostería y concreto reforzado, y los clasifica en cinco grados, enumerados de 1 a 5 , en los que el primer grado es daño débil o sin daño, y el último, la destrucción de la edificación (tabla 3).
Para localizar las edificaciones averiadas por cada sismo se georreferenciaron los planos históricos de cada época, así como la imagen satelital de la ciudad, obtenida a partir de Google Earth, y luego se digitalizaron los predios de cada plano para superponerlos sobre la imagen.

Tabla 3. Tipo de estructura y vulnerabilidad según la escala EMS-98

\begin{tabular}{|c|c|}
\hline & Clasificación del daño en edificios de mampostería \\
\hline $\begin{array}{l}\text { Grado 1. Sin daños a daños leves } \\
\text { (sin daño estructural, daño no estructural leve) }\end{array}$ & $\begin{array}{l}\text { Grietas muy delgadas en muy pocos muros; caída de pequeños pedazos de revestimiento; caída de rocas } \\
\text { sueltas desde la parte alta de edificios en muy pocos casos. }\end{array}$ \\
\hline $\begin{array}{l}\text { Grado 2. Daños moderados } \\
\text { (daño estructural leve, daño no estructural moderado) }\end{array}$ & Grietas en muchos muros; caída de pedazos grandes de revestimiento; colapso parcial de chimeneas. \\
\hline $\begin{array}{l}\text { Grado 3. Daños sustanciales a severos } \\
\text { (daño estructural moderado, daño no estructural severo) }\end{array}$ & $\begin{array}{l}\text { Grietas largas y extensas en muchos muros; } \\
\text { caída de tejas; fractura de las chimeneas; fallo de los elementos individuales no estructurales (tabiques, } \\
\text { divisiones, fachadas). }\end{array}$ \\
\hline $\begin{array}{l}\text { Grado 4. Daños muy severos } \\
\text { (daño estructural severo, daño no estructural muy severo) }\end{array}$ & Fallo serio de los muros; fallo estructural parcial de techos y pisos. \\
\hline $\begin{array}{l}\text { Grado 5. Destrucción } \\
\text { (daño estructural muy severo) }\end{array}$ & Colapso total o casi total. \\
\hline \multicolumn{2}{|r|}{ Clasificación del daño en edificios de concreto reforzado } \\
\hline $\begin{array}{l}\text { Grado 1. Sin daños a daños leve } \\
\text { (sin daño estructural, daño no estructural leve) }\end{array}$ & $\begin{array}{l}\text { Grietas delgadas en el revestimiento sobre elementos de la estructura o en la base de los muros; grietas } \\
\text { delgadas en particiones y tabiques. }\end{array}$ \\
\hline $\begin{array}{l}\text { Grado 2. Daños moderados } \\
\text { (daño estructural leve, daño no estructural moderado) }\end{array}$ & $\begin{array}{l}\text { Grietas en columnas y vigas y en muros estructurales; grietas en particiones y tabiques; caída de revestimiento } \\
\text { frágil y guarnecido; caída de mortero en las uniones de paneles de muros. }\end{array}$ \\
\hline $\begin{array}{l}\text { Grado 3. Daños sustanciales a severos } \\
\text { (daño estructural moderado, daño no estructural severo) }\end{array}$ & $\begin{array}{l}\text { Grietas en columnas y uniones entre columnas y vigas de la estructura en la base y en las uniones de muros } \\
\text { acoplados; desconchamiento del revestimiento de hormigón, torcedura de varillas de refuerzo; grandes grietas } \\
\text { en muros de particiones y en tabiques, fallo de tabiques individuales. }\end{array}$ \\
\hline $\begin{array}{l}\text { Grado 4. Daños muy severos } \\
\text { (daño estructural severo, daño no estructural muy severo) }\end{array}$ & $\begin{array}{l}\text { Grandes grietas en elementos estructurales y fractura de barras corrugadas; fallos en la juntura de vigas } \\
\text { reforzadas; inclinación de columnas; colapso de algunas columnas o de un único piso superior. }\end{array}$ \\
\hline $\begin{array}{l}\text { Grado 5. Destrucción } \\
\text { (daño estructural muy severo) }\end{array}$ & Colapso de la planta baja o de partes de edificios. \\
\hline
\end{tabular}


Finalmente, se superpusieron las edificaciones averiadas por todos los sismos en un plano, con el fin de evidenciar zonas afectadas por daños repetitivos.

\section{Resultados}

Sismo del 20 de enero de 1834: ocurrió a las 7:00 a.m. hora local (12:00 UTC), su magnitud fue de 6,7 Mw, tuvo profundidad superficial y se asocia al sistema de fallas de Afiladores. En Pasto quedaron destruidas y averiadas casas, edificios e iglesias, como la de San Sebastián, San Francisco, Santo Domingo y Santiago. Bajo los escombros de las edificaciones murieron cincuenta personas y hubo un número similar de heridos.

Cuando ocurrió este sismo, Pasto apenas contaba con setenta manzanas distribuidas a lo largo de ocho cuadras en sentido norte-sur, entre las que hoy se conocen como carrera 22 y carrera 28 , y doce cuadras en sentido oriente-occidente desde el río Pasto hasta la calle 11 en el sector de Santiago (Fonseca, 2009; Narváez, 1997). Esta información se basa en el plano elaborado en 1816 por Alejandro Vélez, y encargado por Pablo Morillo, aunque algunos autores atribuyen la autoría de dicho plano a Francisco José de Caldas, quien visitó Pasto en varias ocasiones, la primera vez en agosto de 1801, fecha en que elaboró un plano que no ha sido encontrado, y se dice que es posible que este haya estado entre los documentos incautados a Caldas por el general español Pascual Enrile, segundo en el mando de Pablo Morillo (Bastidas, 2000). Con el fin de contextualizar cómo era la ciudad en esa época, en la figura 4 se presentan los predios existentes según el plano de 1816, digitalizados y superpuestos sobre una imagen de satélite de la ciudad, tomada el 5 de enero de 2015 (DigitalGlobe), obtenida del programa Google Earth.

Respecto al tamaño de la población, la ciudad contaba con aproximadamente 10000 habitantes, calculados a partir de los datos proporcionados por el censo de 1797 del gobernador Diego Antonio Nieto, quien reportó una cifra total de 12465 habitantes (Bastidas, 2000), y por el censo de 1843, mencionado por Sergio Elías Ortiz (1929), en el que la cifra resultante fue de 9688 habitantes.

En esa época, la ciudad estaba decaída arquitectónicamente y su desarrollo urbano paralizado debido a que, a comienzos del siglo XIX, el apoyo del Gobierno de Pasto a la Corona española y la resistencia a la causa indepen- dentista generaron una guerra civil que dejó a la ciudad casi destruida. El coronel británico John Potter Hamilton, quien estuvo en Popayán en 1824, dijo acerca de Pasto:

Según relatan algunos viajeros, la provincia de Pasto presenta ahora imagen desolada de lo que fue la más feroz de las guerras civiles. Dicen que solo se ven por todas partes las ruinas de casas y de aldeas. Las granjas y estancias, antes esmeradamente cultivadas, se hallan desiertas y casi toda su población o ha muerto o se ha expatriado. (Hamilton, 1995. En Bastidas, 2000)

Posteriormente, cuando el científico francés Jean-Baptiste Boussingault llegó a Pasto el 9 de junio de 1831, encontró una ciudad desolada, casas abandonadas y la población diezmada. El claustro de los jesuitas y las casas más grandes habían servido de cuartel durante las guerras:

La población estimada en 20.000 almas en la época de su esplendor había quedado reducida a 8.000. Por todas partes las mismas ruinas que yo había visto en una época anterior en lo más fuerte de la guerra; las casas tienen sin embargo una bella apariencia y la mayoría están deshabitadas. (Boussingault, 1985. En Bastidas, 2000)

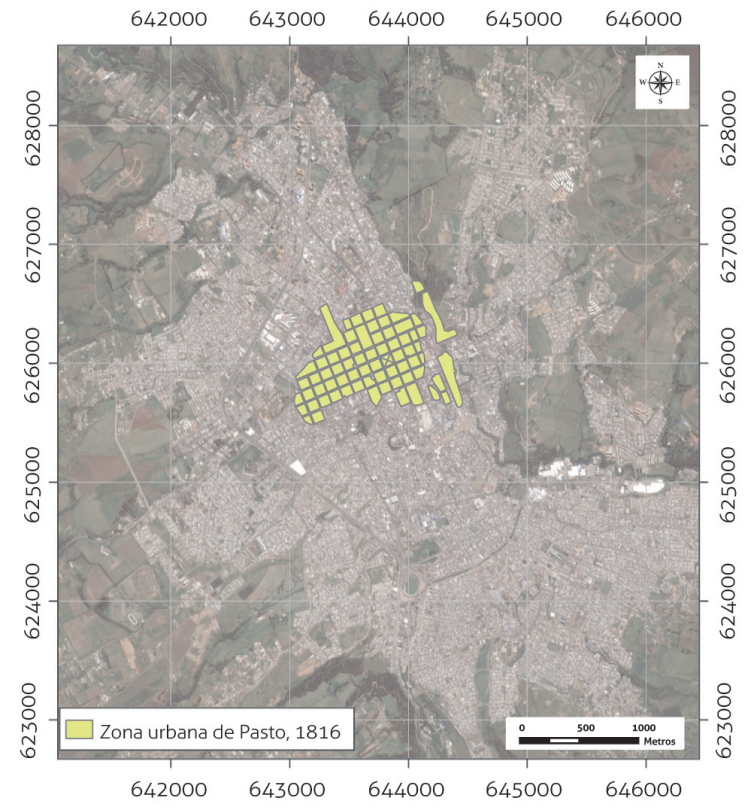

Figura 4. Zona urbana de Pasto en 1816

Fuente: Bastidas (2000). Modificado por Cifuentes y Sarabia (2013) 
De este modo, se entiende que, cuando ocurrió el sismo, la ciudad se encontraba en malas condiciones arquitectónicas, principalmente debido a la guerra, lo cual pudo haber aumentado la vulnerabilidad constructiva. En lo que respecta a los materiales de construcción empleados en la edificación de viviendas a inicios del siglo XIX, las características generales que se observaban en las viviendas de la ciudad se expresan de la siguiente manera: casas "bajas" y de "alto y bajo", construidas de paredes de tapia o adobe crudo, con techo de teja de barro cocido, empañetadas y blanqueadas con cal (Narváez, 1997).

Sismo del 26 de octubre de 1935: ocurrió a las 8:15 de la noche hora local (27 de octubre de 1935, 01:15 UTC), su magnitud fue 5,9 $\mathrm{Mw}$, tuvo profundidad superficial y se asocia al sistema de fallas de Romeral. En Pasto, algunas construcciones presentaron daños leves y moderados, como fisuras y grietas en muros y daños en los techos. También se agravaron los daños que había causado el sismo del 7 de agosto de ese mismo año en la ciudad.

Teniendo en cuenta que los sismos de 1935 y 1947 ocurrieron en épocas muy cercanas, la contextualización histórica del sismo de 1935 se realizó junto con la del sismo de 1947 después de la breve descripción de este último.

Sismo del 14 de julio de 1947: ocurrió a las 2:00 de la mañana hora local (7:00 UTC), su magnitud fue 6,1 Mw, tuvo profundidad superficial y al igual que el evento anterior, se asocia al sistema de fallas de Romeral. La sacudida produjo el colapso de construcciones en las poblaciones de Pasto, Genoy, Obonuco y Matituy en el departamento de Nariño. Algunos de los principales efectos en Pasto fueron daños en las torres y estructura de las iglesias de San Felipe, Pandiaco y Santiago; colapso de los muros de cerramiento del cementerio; el Hospital San Pedro tuvo que ser demolido; hubo numerosas grietas y desperfectos en el palacio Municipal, el palacio de la Gobernación, la plaza de mercado, el matadero municipal, que estaba en construcción, la Universidad de Nariño y el Colegio San Francisco Javier. Según datos de la Alcaldía, fue necesario demoler 500 casas de adobe o de ladrillo sin refuerzo (ejemplos en figura 5). Se produjeron deslizamientos en el antiguo camino de Pasto a Aranda y grietas en Pandiaco, ambos barrios ubicados en el norte de la ciudad.

Respecto al área urbana existente en 1945, el límite suroriental de la ciudad era el Batallón Boyacá y el barrio El Ejido, considerados como zonas rurales; hacia el norte, terminaba en el cementerio Las Cuadras, hoy Hospital Infantil; hacia el occidente se encontraba Anganoy, que actualmente es un barrio de la comuna $8, y$ al oriente finalizaba en Cujacal, que es un barrio de la comuna 12 (Academia Nariñense de Historia, 1999).

Para contextualizar cómo era la ciudad cuando ocurrieron los sismos de 1935 y 1947, se utilizó el mapa aerofotogramétrico del año 1955 (Instituto Geográfico Agustín Codazzi, 1955), que fue el más cercano que se encontró a la fecha de ocurrencia de estos eventos. Los predios existentes en ese mapa se digitalizaron y se superpusieron a la imagen satelital tomada el 5 de enero de 2015 (DigitalGlobe), obtenida del programa Google Earth (figura 6).

Debido al crecimiento comercial e industrial de la ciudad, lo que demandaba nuevas construcciones, vías y una gran cantidad de mano de obra, la ciudad empezó a expandirse, y con ello se crearon nuevos barrios, como el Obrero, en 1935, y el Centenario, en 1940 (Academia Nariñense de Historia, 1999). 


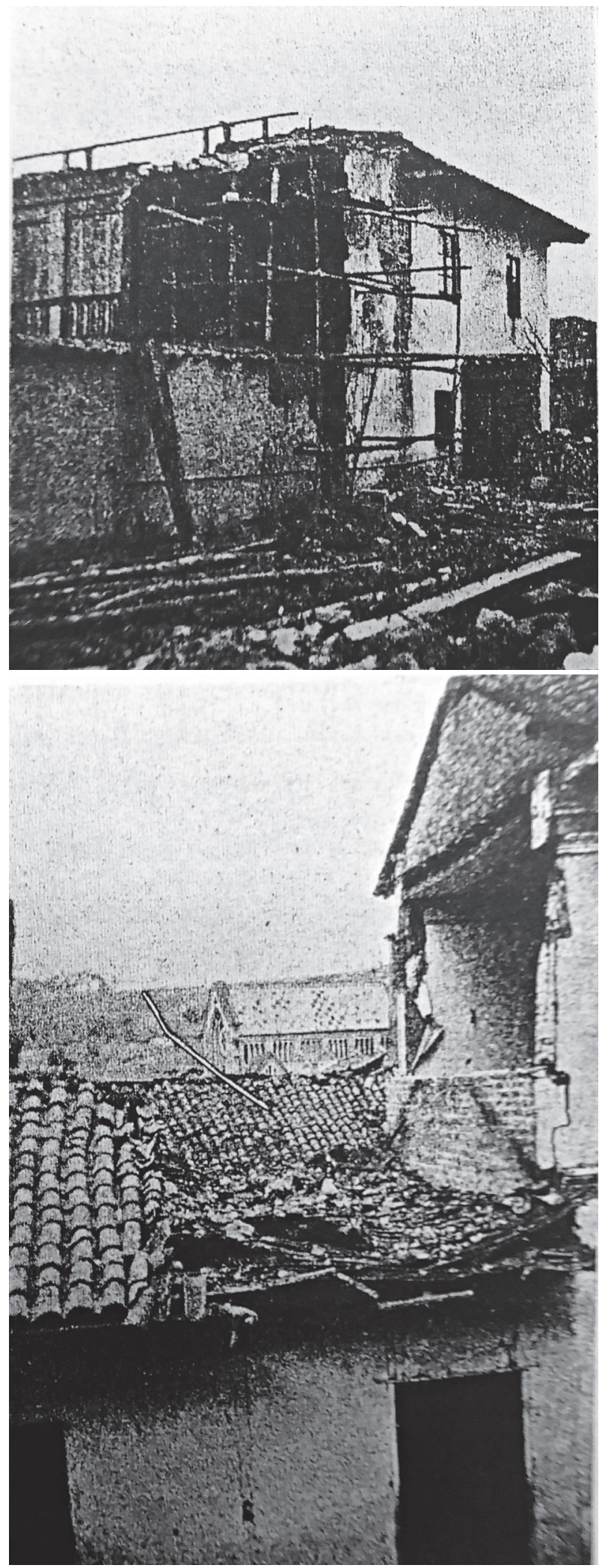

Figura 5. Colapso de muros de viviendas en Pasto Fuente: Ramírez (1948)

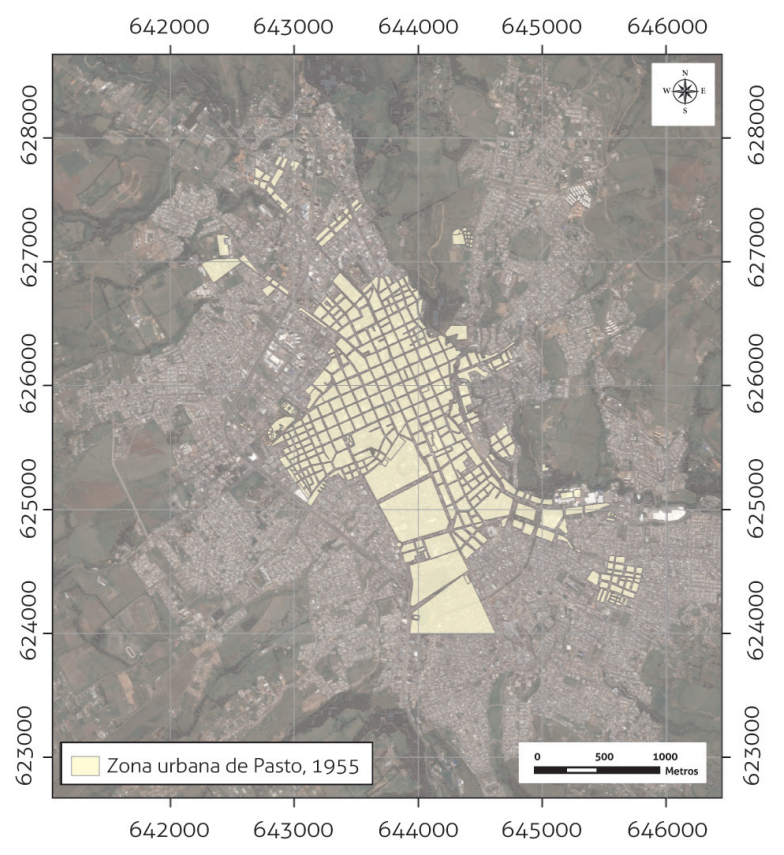

Figura 6. Zona urbana de Pasto en 1955

Fuente: IGAC (1955). Modificado por Cifuentes y Sarabia (2013)

Según el censo de viviendas y edificios del departamento de Nariño realizado en 1951, en Pasto había un total de 5492 edificios en la cabecera, cifra significativa si se compara con los 2909 reportados en el censo de 1938. El crecimiento de la ciudad también se reflejó en el aumento de la población urbana, que pasó de 27504 habitantes, en 1938, a 48853 en 1951 (DANE, 1954).

A pesar del crecimiento y avance de la ciudad, la mayoría de las edificaciones y viviendas seguían siendo sencillas y conservaban los materiales tradicionales, como el adobe, bahareque y ladrillo cocido, con tejas de barro, como se presenta en la tabla 4. 
Tabla 4. Edificios en Pasto según el material predominante

\begin{tabular}{|c|c|c|c|c|}
\hline & Uso & Cabecera & Para vivienda & Otros usos \\
\hline \multirow{5}{*}{ Pisos } & Cemento o baldosa & 365 & 287 & 78 \\
\hline & Ladrillo & 3,092 & 2,974 & 118 \\
\hline & Madera & 1,717 & 1,537 & 180 \\
\hline & Tierra & 297 & 280 & 17 \\
\hline & Otros & 21 & 17 & 4 \\
\hline \multirow{5}{*}{ Muros } & Bloque cemento & 53 & 34 & 19 \\
\hline & Ladrillo & 567 & 482 & 85 \\
\hline & Madera & 35 & 32 & 3 \\
\hline & Adobe y bahareque & 4,828 & 4,539 & 289 \\
\hline & Otros & 9 & 8 & 1 \\
\hline \multirow{5}{*}{ Tejados } & Teja de barro cocido & 5,283 & 4,915 & 368 \\
\hline & Cemento o asbesto & 129 & 107 & 22 \\
\hline & Teja metálica & 21 & 17 & 4 \\
\hline & Paja y similar & 19 & 19 & - \\
\hline & Otros & 40 & 37 & 3 \\
\hline \multicolumn{2}{|r|}{ Total } & 5492 & 5,095 & 397 \\
\hline
\end{tabular}

Fuente: DANE (1954)

\section{Dıscusı́ón}

Después de conocer cómo era la configuración urbana y la tipología constructiva en Pasto durante las épocas en que ocurrieron los tres eventos sísmicos mencionados, se analizó la vulnerabilidad y el grado de daño de las edificaciones afectadas, de acuerdo con los criterios definidos en la Escala Macrosísmica Europea de 1998 (EMS-98).

Según Calpa et al. (2001), a partir del análisis del grado de daño, que es un factor indispensable para asignar el grado de intensidad a un sitio, se busca ubicar las zonas de la ciudad que por la recurrencia de daños de diferentes sismos podrían indicar efectos locales en la ciudad. Para esto es importante relacionar varios factores, como el material de las edificaciones, el estado de las mismas y la clase de vulnerabilidad.

En el anexo B se encuentra la descripción y asignación de grado de daño en las construcciones de los tres sismos considerados. Para una mejor lectura de la información, se elaboró una tabla resumen por evento que reúne las siguientes características: nombre de la edificación afectada (Nombre), tipo de material o estado de conservación de la edificación (Materiales-conservación), descripción del daño de cada edificación afectada (Tipo de daño), clase de vulnerabilidad (Vul.) y grado de daño (Grado). En la primera columna de la tabla se incluye un campo llamado "N.", que es el código con el cual cada construcción está identificada en el respectivo mapa. 
Grado de daño ocasionado por el sismo de 1834: en total se localizaron veintitrés construcciones afectadas entre casas, edificios e iglesias, que se localizaron en la imagen satelital, en la que se sobrepusieron las manzanas que existían en el año 1816. Debido a la falta de información, en algunos casos no fue posible asignar la clase de vulnerabilidad a ciertas edificaciones, por lo cual se tuvieron en cuenta las descripciones generales de los materiales de construcción empleados a comienzos del siglo XIX, mencionadas por algunos autores (e. g., Narváez, 1997; Cerón y Ramos, 1997; Bastidas, 2000), y que prácticamente se reducen a adobe, bahareque y pesados techos de teja de barro, lo que correspondería a clases de vulnerabilidad A o B.
En la figura 7 están localizadas y enumeradas las construcciones afectadas, simbolizadas con su respectivo grado de daño, y que se encuentra en el anexo B. La escala del mapa abarca las iglesias de Chapal, Anganoy y Pandiaco, que en esa época eran pueblos indígenas y no estaban dentro del casco urbano de Pasto.

De las veintitrés construcciones que fue posible localizar, dieciséis de ellas resultaron con grado de daño 3 o 4, que corresponden a daño severo y muy severo, respectivamente, y la mayoría se localizaron al sur de la plaza de Nariño. Seis edificaciones resultaron con grado de daño 2, que corresponde a daño moderado, y solamente una construcción resultó con grado de daño 5 , que corresponde a destrucción.

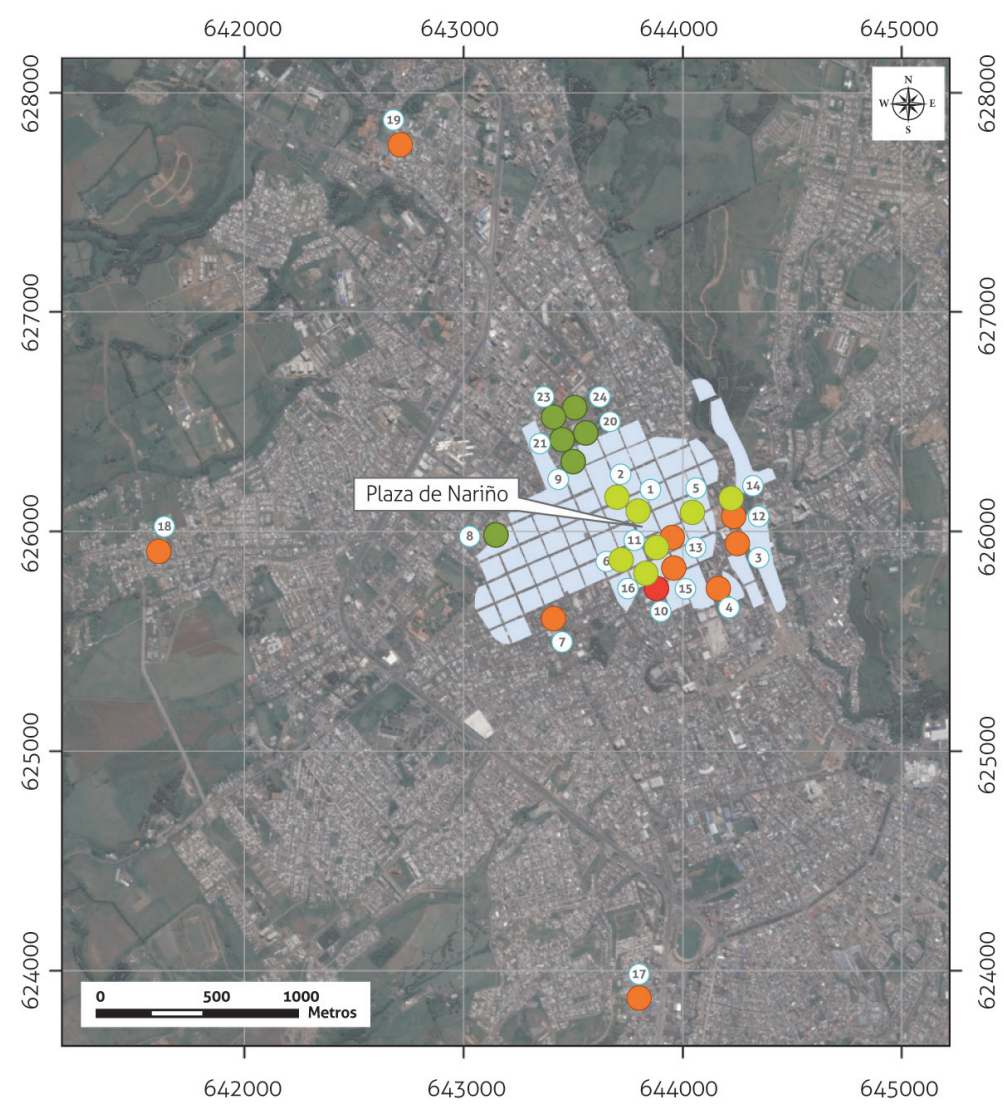

Figura 7. Mapa de grado de daño ocasionado por el sismo de 1834 Fuente: Cifuentes y Sarabia (2013)

\section{CONVENCIONES}

Grado de daño

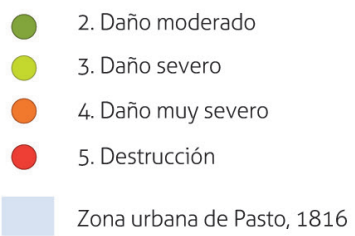

INFORMACIÓN DE REFERENCIA

Datos utilizados: elaboración propia Sistema de coordenadas: MACNA Colombia Oeste Proyección: Transversa de Mercator Datum: D_MAGNA

Mapa de base: Google Earth

Imagen de satélite: DigitalGlobe, 05/01/2015 
Grado de daño ocasionado por el sismo de 1935: en total se localizaron catorce construcciones entre casas, iglesias y edificios, de las cuales doce resultaron con grado de daño 3, que corresponde a daño severo, y dos resultaron con daño moderado. El único dato que se conoce acerca de destrucción de edificaciones en la ciudad es el que informa acerca del colapso de una vivienda, de la que se desconoce la ubicación exacta, aunque este se puede considerar un caso aislado. La distribución espacial de los daños está concentrada especialmente al sur de la plaza de Nariño, como se observa en la figura 8.

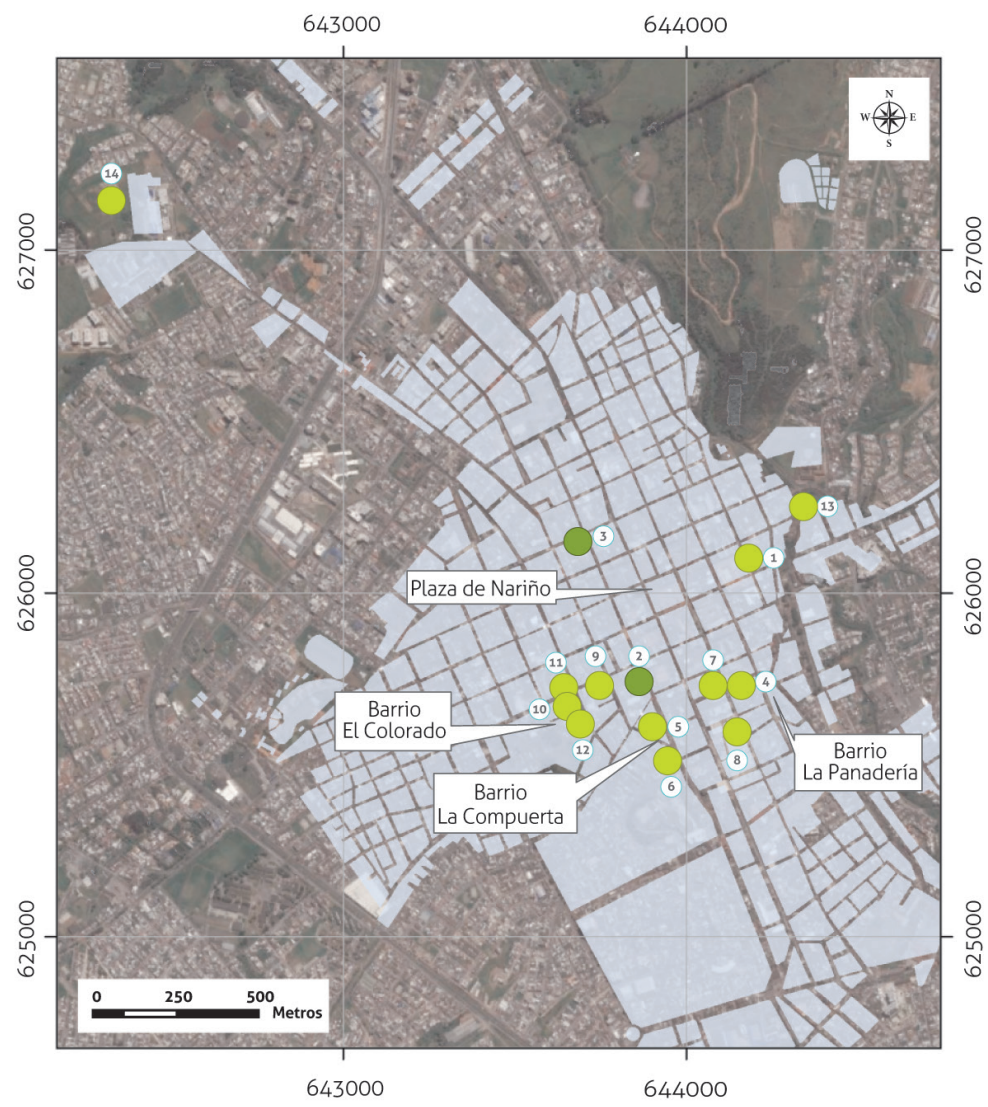

Figura 8. Mapa de grado de daño ocasionado por el sismo de 1935 Fuente: Cifuentes y Sarabia (2013)

\section{CONVENCIONES}

Grado de daño

2. Daño moderado

3. Daño severo

Zona urbana de Pasto, 1955

INFORMACIÓN DE REFERENCIA

Datos utilizados: elaboración propia

Sistema de coordenadas: MAGNA Colombia Oeste

Proyección: Transversa de Mercator

Datum: D_MAGNA

Mapa de base: Google Earth

Imagen de satélite: DigitalGlobe, 05/01/2015 
Grado de daño ocasionado por el sismo de 1947: en total se localizaron 32 construcciones averiadas por el sismo, veintiséis de ellas resultaron con grado de daño 3 (severo), cinco con grado 4 (muy severo) y una con grado 2 (moderado). Según Ramírez (1948), algunas viviendas colapsaron, pero no fue posible encontrar su localización exacta.

Las construcciones que no tienen asociada una clase de vulnerabilidad en el anexo B se pueden interpretar como clase A-B, teniendo en cuenta que para esa época aún predominaban materiales como el adobe, bahareque, tapia pisada y ladrillo sin confinar.
En la figura 9 se presenta el mapa con la ubicación de las construcciones afectadas por el sismo y su respectivo grado de daño. El grado 2 se registró en una edificación situada en el centro de la ciudad; el grado 3 estuvo concentrado principalmente en el centro y suroriente de la ciudad; el grado 4 se presentó de una manera aislada en el centro y norte de la ciudad. En el mapa se ubicó el barrio Pandiaco, en el que se reportaron agrietamientos del terreno, y la vía que conduce de Pasto a Aranda, donde, según los reportes, hubo deslizamientos.

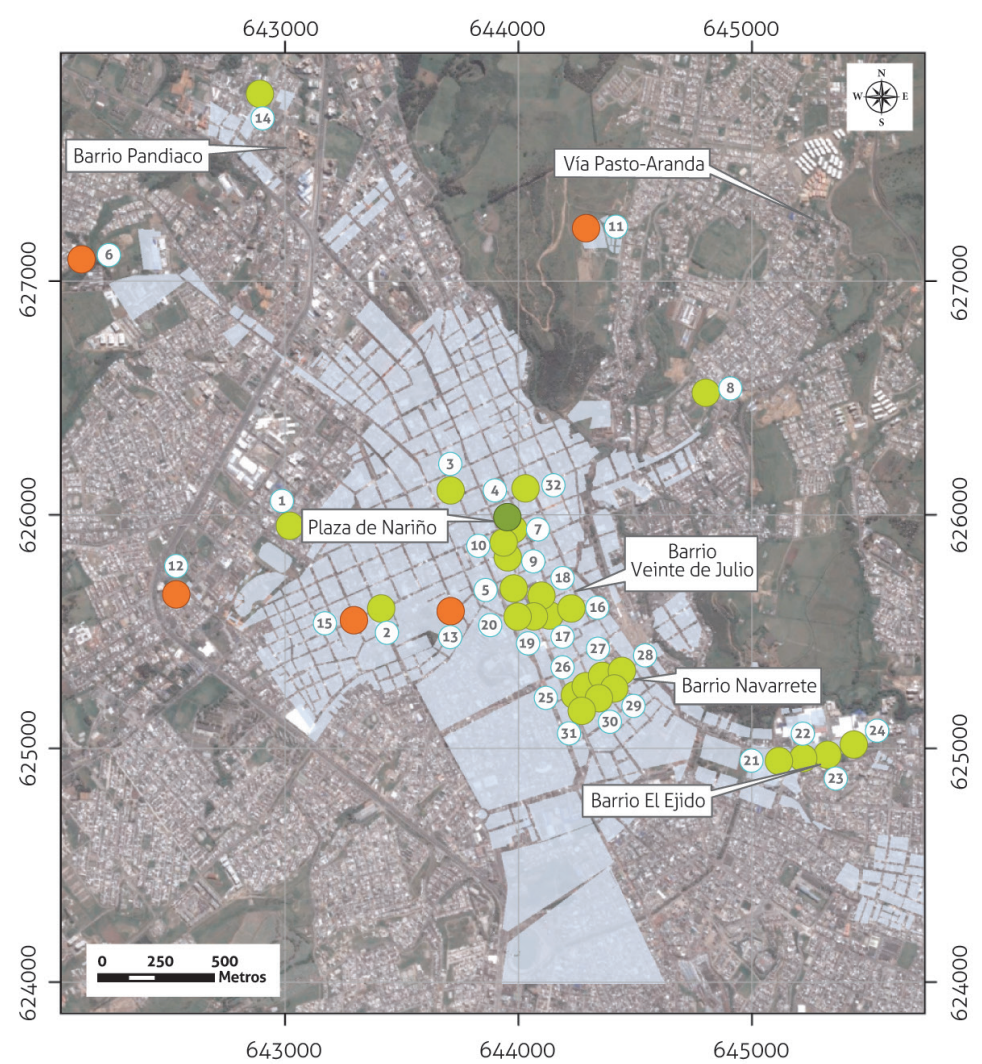

Figura 9. Mapa de grado de daño ocasionado por el sismo de 1947 Fuente: Cifuentes y Sarabia (2013)

\author{
CONVENCIONES \\ Grado de daño \\ 2. Daño moderado \\ 3. Daño severo \\ 4. Daño muy severo \\ Zona urbana de Pasto, 1955 \\ INFORMACIÓN DE REFERENCIA \\ Datos utilizados: elaboración propia \\ Sistema de coordenadas: MAGNA Colombia Oeste \\ Proyección: Transversa de Mercator \\ Datum: D_MAGNA \\ Mapa de base: Google Earth \\ Imagen de satélite: DigitalGlobe, 05/01/2015
}


Mapa de daños: se elaboró un mapa en el que se ubicaron las construcciones afectadas por los tres sismos mencionados, diferenciando cada uno de ellos con variables cartográficas de formas geométricas, con el fin de evidenciar si existían daños sectorizados y recurrentes en la ciudad (figura 10). En el mapa de observa que el centro y sureste de la ciudad son las zonas que principalmente han presentado daños por sismos, con grado de daño predominante 3 (severo).

En la figura 11 se presenta un mapa con el detalle de esa área, encerrada en un rectángulo rojo, en la que se evidencia la recurrencia de daños por los tres sismos. Esa área corresponde a la actual Comuna 1, que ocupa el centro de la ciudad e incluye barrios como Centro, La Panadería, San Agustín Centro, San Andresito y el sector del 20 de Julio (actual plaza del Carnaval).

El área que se enmarca en el polígono rojo corresponde a la más antigua de la ciudad, y, según varias fuentes bibliográficas (e. g. Narváez, 1997; Bastidas, 2000), allí las construcciones son muy vulnerables debido a su an- tigüedad y a la mezcla de materiales de construcción. De hecho, en la figura 12 es posible advertir la alta vulnerabilidad de varias construcciones que había en el centro de la ciudad y se han derribado para dar paso a la ampliación de vías, como la carrera 27. En la fotografía se observan muros de una misma edificación con mezcla de materiales, como adobe y tapia, sin evidencia de confinamiento o refuerzo.

De esta manera, no es preciso hacer una asociación directa de los daños recurrentes por sismos en el sector del centro de la ciudad con posibles efectos de sitio, ya que ese sector es el más antiguo de la ciudad y sus edificaciones son las más vulnerables.

Aun así, hay que destacar que otras zonas antiguas de la ciudad, ya existentes en 1816 y ubicadas al norte y occidente de la plaza de Nariño, no presentaron averías significativas por los sismos estudiados. Estos aspectos deben ser investigados y cotejados con estudios de tipo geotécnico y geofísico, entre otros.

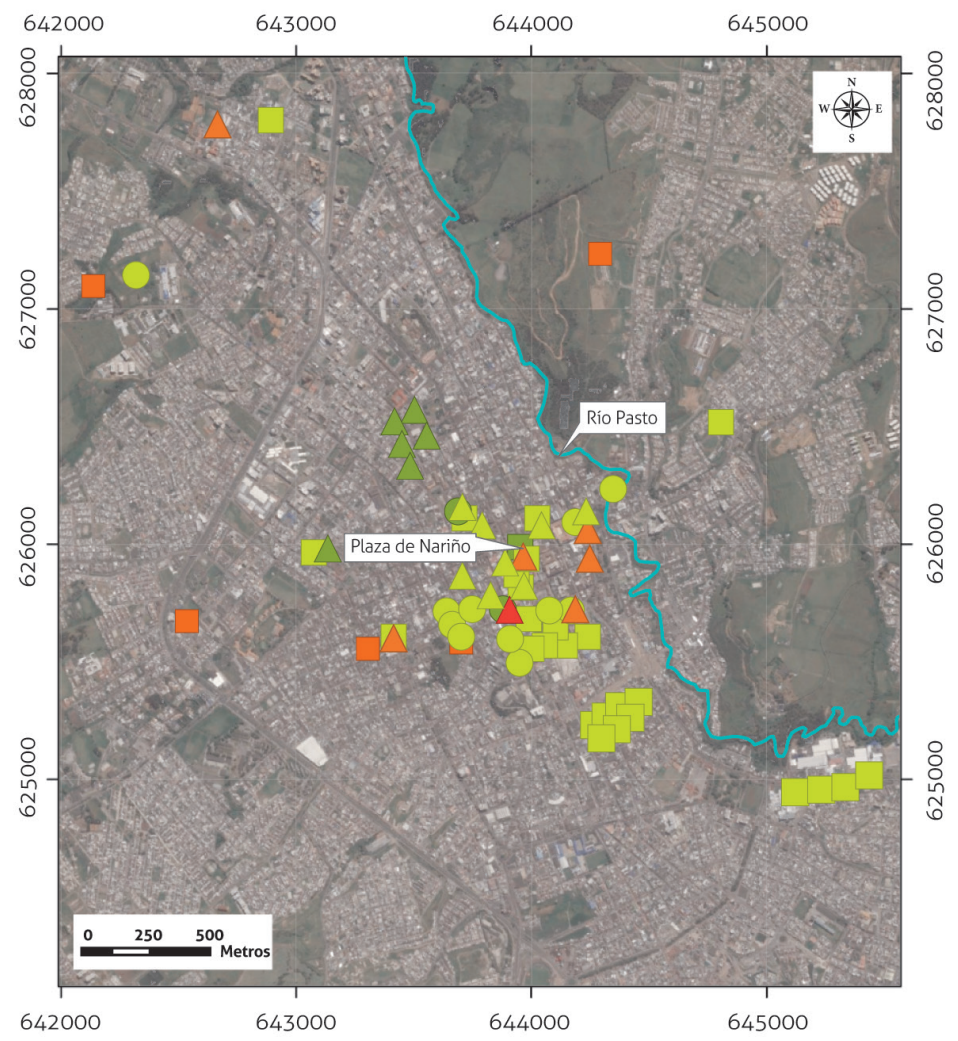

\section{CONVENCIONES - GRADO DE DAÑO}

Sismo de 1834

2. Daño moderado

3. Daño severo

4. Daño muy severo

5. Destrucción

Sismo de 1935

2. Daño moderado

3. Daño severo

\section{Sismo de 1947}

2. Daño moderado

3. Daño severo

4. Daño muy severo

Río Pasto

\section{INFORMACIÓN DE REFERENCIA}

Datos utilizados: elaboración propia Sistema de coordenadas: MAGNA Colombia Oeste Proyección: Transversa de Mercator Datum: D_MAGNA

Mapa de base: Google Earth

Imagen de satélite: DigitalGlobe, 05/01/2015

Figura 10. Mapa general del grado de daño ocasionado por sismos históricos en Pasto Fuente: Cifuentes y Sarabia (2013) 


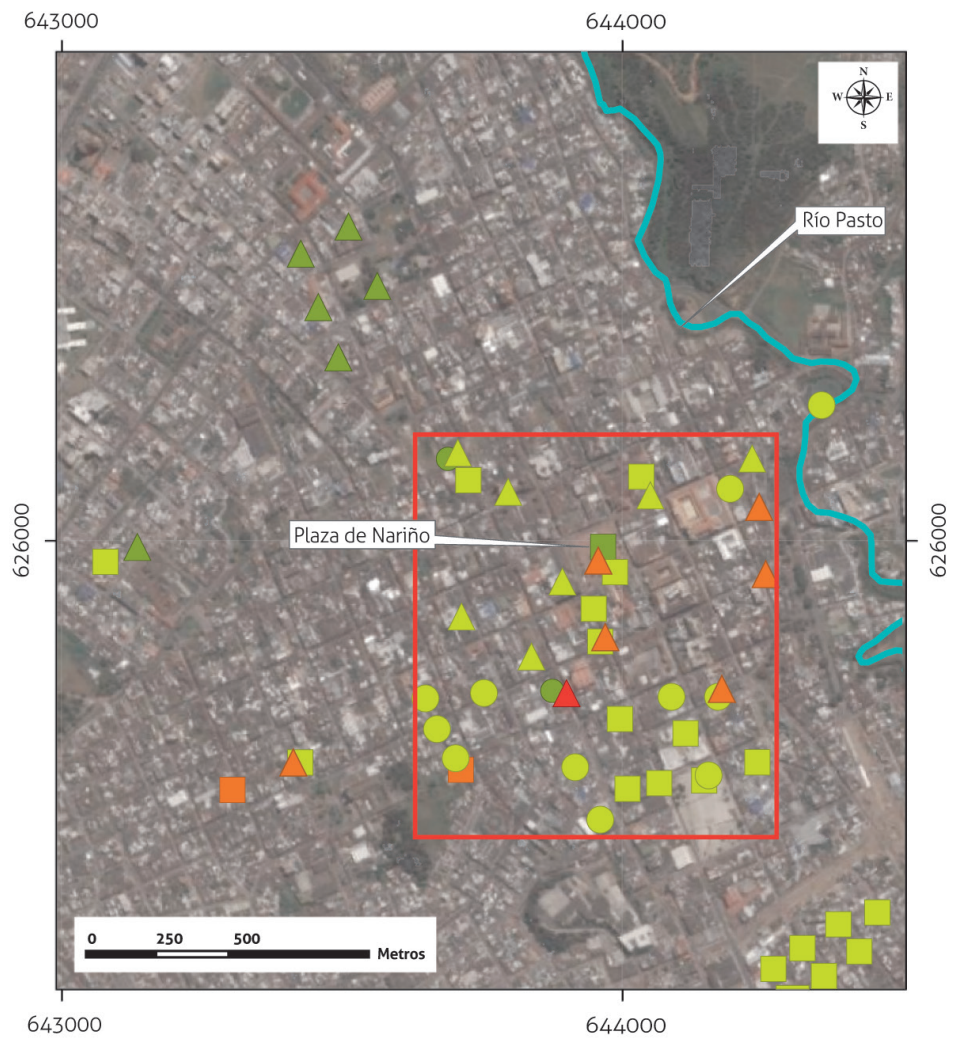

\section{CONVENCIONES - GRADO DE DAÑO}

\section{Sismo de 1834}

2. Daño moderado

3. Daño severo

4. Daño muy severo

5. Destrucción

\section{Sismo de 1935}

2. Daño moderado

3. Daño severo

\section{Sismo de 1947}

2. Daño moderado

3. Daño severo

4. Daño muy severo

$\checkmark$ Río Pasto

\section{INFORMACIÓN DE REFERENCIA}

Datos utilizados: elaboración propia

Sistema de coordenadas: MACNA Colombia Oeste

Proyección: Transversa de Mercator

Datum: D_MAGNA

Mapa de base: Google Earth

Imagen de satélite: DigitalGlobe, 05/01/2015

Figura 11. Mapa detallado del grado de daño ocasionado por sismos históricos en Pasto Fuente: Cifuentes y Sarabia (2013)

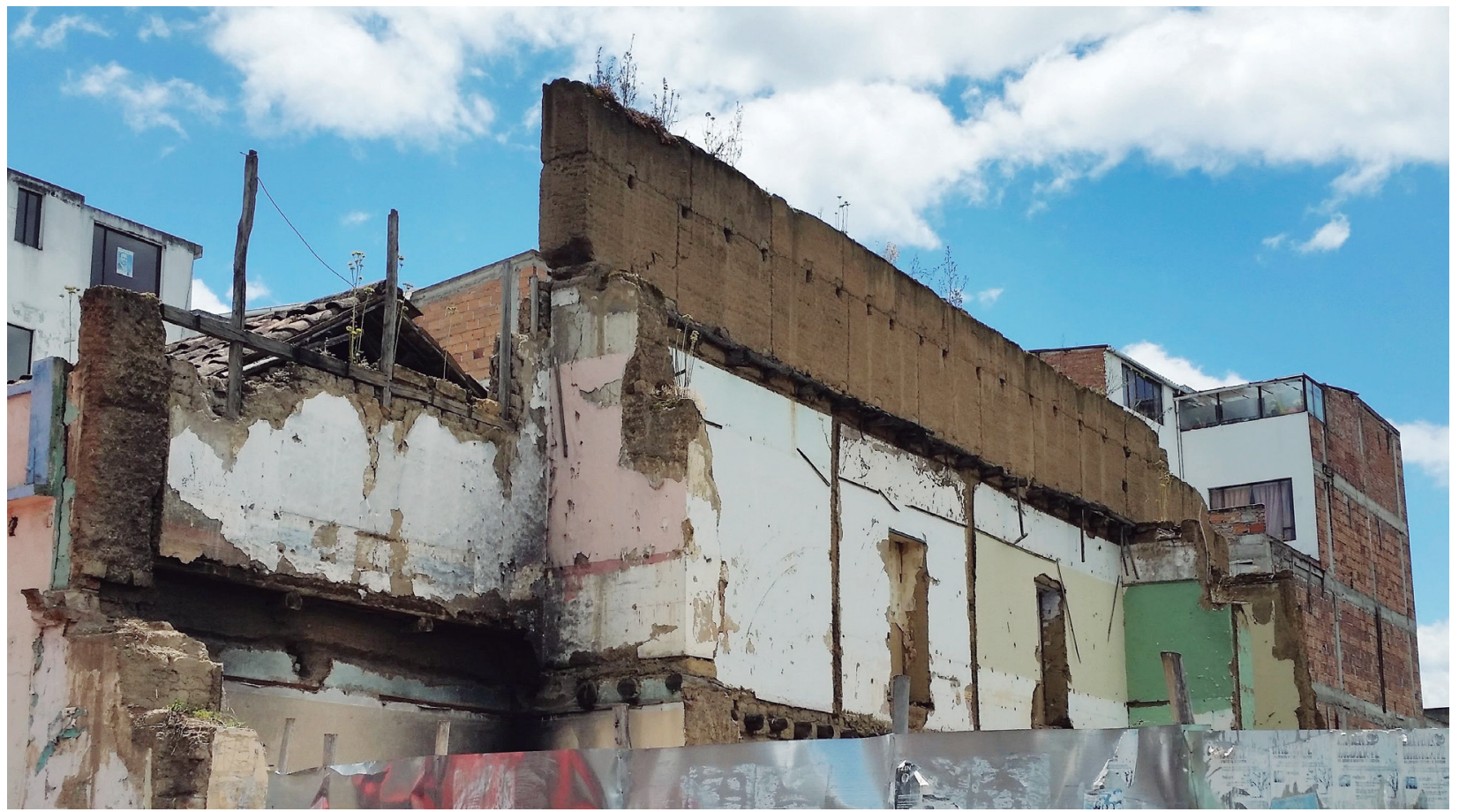

Figura 12. Mezcla de materiales en muros de viviendas en Pasto Fuente: Archivo personal. Sarabia (2017) 


\section{Conclusiones}

Los sismos históricos que han afectado de manera significativa a Pasto han sido eventos superficiales provenientes de fuentes sismogénicas de carácter regional, como el sistema de fallas de Afiladores (20 de enero de 1834) y el sistema de fallas de Romeral (26 de octubre de 1935 y 14 de julio de 1947).

Se obtuvieron buenas fuentes de información sobre la historia urbana de Pasto relacionada con los tres sismos estudiados, que permitieron conocer la configuración espacial de la ciudad y determinar los tipos de materiales de construcción utilizados en la mayoría de las construcciones afectadas, su estructura y estado de conservación, para, de este modo, evaluar la vulnerabilidad y el grado de daño de las mismas.

La distribución de daños en el mapa del sismo de 1834 refleja concentración de la mayor afectación, especialmente hacia el sur y el oriente de la plaza de Nariño, con excepción del daño severo presentado en la iglesia de Santiago, localizada al suroccidente de la plaza. Se reportaron daños leves en la iglesia de San Andrés y el barrio San Francisco, ubicados en el extremo norte de la ciudad de esa época.

El sismo de 1935 causó daños moderados en la ciudad (grados de daño 2 y 3 ). Teniendo en cuenta la traza urbana existente en esa época, los daños estuvieron concentrados en un sector pequeño, en los antiguos barrios El Colorado y la Compuerta, cercanos a la actual plaza del Carnaval, y en el barrio La Panadería. Cuando sucedió ese evento, en la ciudad se evidenciaban algunos daños leves causados por el sismo del 7 de agosto de ese mismo año.

El sismo de 1947 causó graves daños en la ciudad, y su distribución fue similar a la del sismo de 1834, si se tiene en cuenta que se localizaron principalmente al sur y el oriente de la plaza de Nariño, aunque esta vez en mayor cantidad, dado el crecimiento de la ciudad. También se reportaron daños aislados en otros sectores.

Las edificaciones afectadas por los tres sismos fueron básicamente inmuebles de baja altura (máximo tres pisos), de mampostería, construidos con materiales como adobe, tapia y ladrillo sin refuerzo, muchas de ellas con cubiertas pesadas de tejas de barro, lo cual las hacía más vulnerables.
La única zona de la ciudad donde se evidenció la recurrencia de daños a causa de los tres sismos fue en los barrios Centro, La Panadería, San Agustín Centro, San Andresito y el antiguo sector del 20 de Julio, actualmente plaza del Carnaval, que hacen parte de la Comuna 1. Esta zona corresponde al sector más antiguo de la ciudad, por lo cual es probable que los daños se presentaran debido a la alta vulnerabilidad de las edificaciones, construidas con materiales poco resistentes, mezcla de diversos materiales y técnicas inapropiadas. Aun así, no se descarta la existencia de algún efecto de respuesta local del suelo debido a que, en otras zonas antiguas de la ciudad que tienen la misma vulnerabilidad constructiva, no se reportaron daños por ninguno de los tres sismos, o los daños fueron leves.

Se sugiere realizar estudios específicos en la zona más afectada por los sismos con el fin de determinar si los daños reportados tuvieron relación con la respuesta local del suelo, o si correspondió a la vulnerabilidad propia de las estructuras.

\section{REFERENCIAS BIBLIOGRÁFICAS}

Academia Nariñense de Historia. (1999). Manual de historia de Pasto, tomo III. Pasto: Alcaldía municipal de Pasto, Concejo municipal de Pasto.

Altez, R. y Laffaille, J. (2006). La microzonificación sismo-histórica como complemento fundamental de la evaluación de amenaza sísmica. Revista de la Facultad de Ingeniería de la Universidad Central de Venezuela, 21(4), 117-127.

Asociación Colombiana de Ingeniería Sísmica -(AIS) (2010). Reglamento colombiano de construcción sismo resistente, NSR-10. Bogotá: Ministerio de Ambiente, Vivienda y Desarrollo Territorial.

Bastidas, J. (2000). Historia urbana de Pasto. Bogotá: Ediciones Testimonio.

Calpa, C., Pantoja, J., Alfaro, A. y Van Hissenhoven, R. (2001). Evidencias de efectos locales y mapa de susceptibilidad sísmica en la ciudad de Pasto. Bogotá: XI Jornadas Geotécnicas de la Ingeniería Colombiana y VI Foro sobre Geotecnia de la Sabana de Bogotá.

Cerón, B. y Ramos, M. (1997). Pasto: espacio, economía y cultura. Pasto: Fondo Mixto de Cultura. 
Cifuentes, H. y Sarabia, A. (2007). Estudio macrosísmico del sismo del 14 de julio de 1947, Pasto (Nariño). Ingeominas. Disponible en http://aplicaciones1.sgc.gov. co/Bodega/i_vector/210/01/0000/24413/documento/ pdf/2105244131131000.pdf

Cifuentes, H. y Sarabia, A. (2013). Evaluación del grado de daño en la ciudad de San Juan de Pasto a causa de sismos históricos. Servicio Geológico Colombiano. Disponible enhttp://aplicaciones1.sgc.gov.co/Bodega/i_vector/210/01 /0000/24657/documento/pdf/2105246571101000.pdf

Departamento Administrativo Nacional de Estadística (DANE) (1954). Censo de edificios y viviendas, 1951. Volumen 11: Nariño. Bogotá.

Fonseca, J. (2009). Cartografía de Pasto, 1800-2006. Revista de Arquitectura, 11(1), 57-67.

Gómez, A., Sarabia, A., Arcila, M., Santulin, M. y Stucchi, M. (2016). Earthquake parameters estimation from historical macroseismic data in Colombia. San José: Asamblea Regional Comisión Latinoamericana y del Caribe de Sismología.

Google Earth (2015). Imagen satelital de Pasto. Satélite DigitalGlobe.

Grünthal, G. (2009). Escala Macrosísmica Europea, 1998. Luxemburgo: Cahiers du Centre Européen de Géodynamique et de Séismologie.
Instituto Geográfico Agustín Codazzi (IGAC) (1955). Plano aerofotogramétrico de la ciudad de Pasto. Bogotá: Banco de la República.

Narváez, S. (1997). Evolución urbana de Pasto: siglo XIX. Pasto: Fondo Mixto de Cultura.

Ortiz, S. (1929). A propósito del censo de población de Pasto desde su fundación hasta 1843. Pasto: Boletín de Estudios Históricos.

Ramírez, J. (1948). The Pasto, Colombia earthquake of july 14, 1947. Bulletin of the Seismological Society of America, 38(4), 247-256.

Sarabia, A., Cifuentes, H. y Dimaté, M. (2006). Estudio macrosísmico del sismo del 20 de enero de 1834, Santiago (Putumayo). Ingeominas. Disponible en http://aplicaciones1.sgc.gov.co/Bodega/i_vector/210/01/0000/24413/ documento/pdf/2105244131113000.pdf

Sarabia, A. y Cifuentes, H. (2010). Estudio macrosísmico de los sismos ocurridos al sur del departamento de Nariño en 1935y 1936. Ingeominas. Disponible en http://aplicaciones1.sgc.gov.co/Bodega/i_vector/210/01/0000/24413/ documento/pdf/2105244131127000.pdf

Servicio Geológico Colombiano. Sistema de información de sismicidad histórica de Colombia. Disponible en http://sish.sgc.gov.co/visor/. 
Anexo A. Descripción de Construcciones afectadas por los sismos seleccionados

\begin{tabular}{|c|c|c|c|}
\hline Nombre & Año aproximado de construcción & Dirección actual & Sismo \\
\hline $\begin{array}{l}\text { Iglesia San Juan Bautista } \\
\text { (antigua iglesia Matriz) }\end{array}$ & $\begin{array}{l}\text { La primera construcción data de } 1537 \text {. En } 1669 \text { se dio paso } \\
\text { a la construcción del templo actual, y se finalizó en } 1671 . \\
\text { Remodelada en } 1829,1856,1934 \text { y } 1938 \text {. }\end{array}$ & $\begin{array}{l}\text { Sin cambio de localización. } \\
\text { Calle } 18 \text { con carrera } 25 \text {, esquina. }\end{array}$ & 1834 \\
\hline $\begin{array}{l}\text { Catedral de Pasto (San } \\
\text { Francisco) }\end{array}$ & $\begin{array}{l}\text { Construida por primera vez en } 1560 \text {. Esa iglesia fue } \\
\text { destruida y en } 1899 \text { se inició la construcción de la iglesia } \\
\text { actual, terminada en } 1920 \text {. En el año } 1995 \text { se restableció el } \\
\text { ladrillo de la fachada. }\end{array}$ & $\begin{array}{l}\text { Sin cambio de localización. } \\
\text { Carrera } 26 \text { n. } 17-23 .\end{array}$ & $\begin{array}{l}1834,1935 \\
1947\end{array}$ \\
\hline $\begin{array}{l}\text { Antigua iglesia de San } \\
\text { Sebastián }\end{array}$ & $\begin{array}{l}\text { Construida en } 1744 \text {. Destruida casi en su totalidad por la } \\
\text { serie de sismos de } 1935 \text { y } 1936 .\end{array}$ & $\begin{array}{l}\text { No existe. En su lugar se encuentra la estatua de Santander } \\
\text { en la av. Santander (carrera 22). }\end{array}$ & 1834,1935 \\
\hline $\begin{array}{l}\text { Iglesia de San Sebastián o La } \\
\text { Panadería }\end{array}$ & $\begin{array}{l}\text { La capilla de La Panadería fue concluida en } 1790 \text { y } \\
\text { destruida en } 1936, \text { para dar paso a la construcción de la } \\
\text { actual iglesia de San Sebastián. }\end{array}$ & Carrera 21 n. ${ }^{\circ} 20-20$ & $\begin{array}{l}1834,1935 \\
1947\end{array}$ \\
\hline $\begin{array}{l}\text { Iglesia de Cristo Rey (antigua } \\
\text { Santo Domingo) }\end{array}$ & $\begin{array}{l}\text { Se inició la construcción en } 1572 \text {. En } 1930 \text { se derrumbó } \\
\text { para dar paso a la iglesia actual. }\end{array}$ & $\begin{array}{l}\text { Sin cambio de localización. } \\
\text { Calle } 20 \text { n. }^{\circ} 24 \text { esquina. }\end{array}$ & 1834 \\
\hline Iglesia de San Agustín & $\begin{array}{l}\text { Construida a finales del Siglo XVI. } \\
\text { El actual templo fue construido después del sismo de } \\
1834 .\end{array}$ & $\begin{array}{l}\text { Sin cambio de localización. } \\
\text { Carrera } 24 \text { n. } 16-70 .\end{array}$ & 1834 \\
\hline Capilla de San Andrés & $\begin{array}{l}\text { La construcción de la capilla inició en } 1582 \text { y finalizó en } \\
\text { 1591. Luego, la construcción de la iglesia inició en } 1850 .\end{array}$ & $\begin{array}{l}\text { Sin cambio de localización. } \\
\text { Carrera } 29 \text { n. }{ }^{\circ} 16 \mathrm{~B}-34 .\end{array}$ & 1834 \\
\hline $\begin{array}{l}\text { Antiguo convento de La } \\
\text { Concepción }\end{array}$ & $\begin{array}{l}\text { Fundado en } 1588 \text {. Tuvo refacciones en el siglo XVII, debido } \\
\text { al mal estado en que se hallaba. En } 1864 \text { fue trasladado al } \\
\text { frente del templo San Felipe Neri. }\end{array}$ & $\begin{array}{l}\text { Se encontraba en el sitio que actualmente ocupa la } \\
\text { Gobernación de Nariño. } \\
\text { Calle } 19 \text { con carrera } 24 .\end{array}$ & 1834 \\
\hline Capilla del Portal & - & $\begin{array}{l}\text { Actualmente no existe. Se encontraba en el lugar que hoy } \\
\text { ocupa el edificio de Bomberos. } \\
\text { Calle } 22 \text { con carrera } 23 \text {. }\end{array}$ & 1834 \\
\hline Antigua cárcel & - & $\begin{array}{l}\text { Se encontraba en la manzana que está al sur de la plaza } \\
\text { Nariño, entre carreras } 23 \text { y } 24 \text { y calles } 18 \text { y } 19\end{array}$ & 1834 \\
\hline Iglesia de La Merced & $\begin{array}{l}\text { Su construcción inició en } 1562 \text { y se terminó en 1609. La } \\
\text { iglesia actual data de } 1916 .\end{array}$ & $\begin{array}{l}\text { Sin cambio de localización, } \\
\text { calle } 18 \text { con carrera } 22\end{array}$ & 1834,1935 \\
\hline Antigua casa del Cabildo & 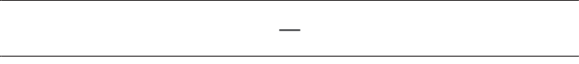 & $\begin{array}{l}\text { Se encontraba en la manzana que está al sur de la plaza } \\
\text { Nariño, entre carreras } 23 \text { y } 24 \text { y calles } 18 \text { y } 19\end{array}$ & 1834 \\
\hline Carnicería & Ya existía a mediados del siglo XVI & $\begin{array}{l}\text { Actualmente no existe. Se encontraba cerca del lugar que hoy } \\
\text { ocupa el edificio de Bomberos. } \\
\text { Calle } 22 \text { con carrera } 23 \text {. }\end{array}$ & 1834 \\
\hline Casa de juego de gallos & - & $\begin{array}{l}\text { Según el plano elaborado por Higinio Muñoz en 1864, estaba } \\
\text { ubicada en la calle 17, entre carreras } 22 \text { y } 23\end{array}$ & 1834 \\
\hline Barrio San Francisco & - & $\begin{array}{l}\text { Hace referencia al barrio que se encuentra al norte de la } \\
\text { iglesia de San Andrés }\end{array}$ & 1834 \\
\hline Iglesia de Pandiaco & - & $\begin{array}{l}\text { Actualmente es un barrio situado en el norte de Pasto } \\
\text { (Comuna 9) }\end{array}$ & 1834 \\
\hline Iglesia de Chapal & - & Calle 11 con carrera 5A & 1834 \\
\hline Iglesia de Canchalá & 一 & Calle 19B con carrera 9D Este & 1834 \\
\hline Iglesia de Anganoy & Se cree que la iglesia fue construida en el siglo XIX & Carrera 33BS con calle $6 \mathrm{~S}$ & 1834 \\
\hline Capilla de Jesús del Río & $\begin{array}{l}\text { La construcción inició en } 1741 . \\
\text { Se incendió en } 1840 .\end{array}$ & $\begin{array}{l}\text { Sin cambio de localización. Capilla anexa al templo San } \\
\text { Felipe Neri. } \\
\text { Calle } 11 \text { n. } 27-31 .\end{array}$ & 1834,1947 \\
\hline $\begin{array}{l}\text { Universidad de Nariño (Colegio } \\
\text { Jesuita, de la Compañía o San } \\
\text { Agustín) }\end{array}$ & Construida en 1712. Refaccionada en 1929. & $\begin{array}{l}\text { Actualmente es la sede central de la Universidad de Nariño. } \\
\text { Carrera } 22 \text { con calle } 19 .\end{array}$ & 1834,1947 \\
\hline Iglesia San Felipe Neri & La construcción inició en 1871 y finalizó en 1894 & Calle 11 con carrera 27 & 1947 \\
\hline Antigua plaza de mercado & $\begin{array}{l}\text { La construcción inició en } 1907 \text { y finalizó en } 1928 \text {. Debido a } \\
\text { incendios ocurridos en la década de los cincuenta y de los } \\
\text { setenta, la edificación quedó destruida. }\end{array}$ & $\begin{array}{l}\text { Es la manzana donde se encuentra ubicado el Banco de la } \\
\text { República y la Biblioteca. Entre carreras } 21 \text { y } 21 \mathrm{~A} \text {, calles } 18 \\
\text { y } 19 .\end{array}$ & 1947 \\
\hline Iglesia de Santiago Apóstol & $\begin{array}{l}\text { Construida a finales del siglo XVI. Reedificada en } 1665 \text { y } \\
\text { nuevamente en } 1796 \text {. En } 1894 \text { fue derruida y ese mismo } \\
\text { año se inició la construcción del nuevo templo. Se finalizó } \\
\text { en } 1897 \text {. }\end{array}$ & $\begin{array}{l}\text { Sin cambio de localización. } \\
\text { Calle } 12 \mathrm{n} .^{\circ} 22 \mathrm{~F}-16 .\end{array}$ & 1947 \\
\hline Palacio de Justicia (Nacional) & Su construcción finalizó en 1945 & Ubicado en la calle 19 con carrera 23 & 1947 \\
\hline Antiguo palacio Municipal & $\begin{array}{l}\text { Su construcción inició en } 1866 \text { y finalizó en } 1926 \text {. Fue } \\
\text { reparado en varias ocasiones. }\end{array}$ & No existe. Se encontraba en la calle 18 con carrera 26. & 1947 \\
\hline Palacio de la Gobernación & Inició su construcción en 1910 y finalizó en 1929 & Ubicado en la calle 19 con carrera 24 & 1947 \\
\hline Hospital Civil & Su construcción finalizó en 1942 & Ubicado en la calle 27 con carrera 24 & 1947 \\
\hline Hospital San Pedro & Su construcción inició en 1922 y finalizó en 1929 & Ubicado en la calle 16 con carrera 43 esquina & 1935,1947 \\
\hline $\begin{array}{l}\text { Cementerio Central Virgen del } \\
\text { Carmen }\end{array}$ & Su construcción finalizó en 1939 & Calle 24, Comuna 9 & 1947 \\
\hline Escuela Industrial & - & Calle 3 con carrera 32 & 1947 \\
\hline Antiguo Matadero Municipal & En 1947 se encontraba en construcción & $\begin{array}{l}\text { Actualmente es el Museo del Carnaval. Calle } 19 \text { con carrera } \\
42 .\end{array}$ & 1947 \\
\hline Colegio San Francisco Javier & Su construcción inició en 1919 y finalizó en 1925 & Calle 20 con carrera 25 & 1947 \\
\hline Barrio Veinte de Julio & - & Carrera 21 entre calles 18 y 20 & 1947 \\
\hline Barrio El Ejido & 一 & Calles $21 \mathrm{~F}$ y $21 \mathrm{E}$ con carreras 7 y $3 \mathrm{~A}$ & 1947 \\
\hline Barrio Navarrete & - & Calles 19 y 22 entre carreras 16 y $17 \mathrm{~A}$ & 1947 \\
\hline Escuela Industrial & - & Calle 3 con carrera 32 & 1947 \\
\hline
\end{tabular}




\section{Anexo B. Descripción de daÑos POR SISMOS}

\section{Sismo del 20 de enero de 1834}

\begin{tabular}{|c|c|c|c|c|c|}
\hline N. ${ }^{\circ}$ & Nombre & Materiales/conservación & Tipo de daño & Vul. & Grado \\
\hline 1 & $\begin{array}{l}\text { Iglesia San Juan Bautista } \\
\text { (antigua iglesia Matriz) }\end{array}$ & $\begin{array}{l}\text { Muros de tapia pisada y cubierta de teja de barro } \\
\text { cocido. El frontis y el pórtico lateral elaborados en } \\
\text { piedra labrada. La torre de mampostería de piedra } \\
\text { regular y ladrillo. }\end{array}$ & $\begin{array}{l}\text { Cayó la torre y el frontis y hubo pequeñas } \\
\text { fisuras en las paredes }\end{array}$ & $A-B$ & 3 \\
\hline 2 & $\begin{array}{l}\text { Catedral } \\
\text { (iglesia de San Francisco) }\end{array}$ & $\begin{array}{l}\text { Tapia pisada. La edificación se encontraba en mal } \\
\text { estado. }\end{array}$ & $\begin{array}{l}\text { Según el gobernador de la provincia de Pasto, } \\
\text { la catedral colapsó, pero este hecho no es } \\
\text { verosímil, ya que fue derribada a finales del } \\
\text { siglo XIX }\end{array}$ & A & 3 \\
\hline 3 & $\begin{array}{l}\text { Antigua iglesia de San } \\
\text { Sebastián }\end{array}$ & $\begin{array}{l}\text { Muros de tapia pisada. Cubierta de madera y teja } \\
\text { de barro. }\end{array}$ & $\begin{array}{l}\text { Quedó semidestruida. Murieron personas bajo } \\
\text { sus ruinas. }\end{array}$ & $A-B$ & 4 \\
\hline 4 & $\begin{array}{l}\text { Iglesia de La Panadería } \\
\text { (San Sebastián) }\end{array}$ & Tapia pisada, adobe o bahareque & Semidestruida. Debía ser reconstruida. & $A-B$ & 4 \\
\hline 5 & $\begin{array}{l}\text { Iglesia de Cristo Rey } \\
\text { (Santo Domingo) }\end{array}$ & $\begin{array}{l}\text { Muros de tapia pisada, arcos y columnas de } \\
\text { mampostería }\end{array}$ & $\begin{array}{l}\text { Según el gobernador de la provincia de Pasto, la } \\
\text { iglesia colapsó, pero este hecho no es verosímil, } \\
\text { ya que fue derribada en } 1930\end{array}$ & $A-B$ & 3 \\
\hline 6 & Iglesia de San Agustín & Calicanto & $\begin{array}{l}\text { Daños en el techo, en la parte del corredor que } \\
\text { da al convento de San Francisco, en las dos } \\
\text { torres, el presbiterio y el claustro occidental. } \\
\text { Debido a los daños que hubo en la iglesia de } \\
\text { Santiago, los servicios de ese templo pasaron a } \\
\text { prestarse en el de San Agustín. }\end{array}$ & $A-B$ & 3 \\
\hline 7 & Iglesia de Santiago & Tapia pisada, adobe o bahareque & $\begin{array}{l}\text { Debido a los daños que hubo, los servicios de } \\
\text { esta iglesia pasaron a prestarse en la de San } \\
\text { Agustín }\end{array}$ & $A-B$ & 4 \\
\hline 8 & Capilla de Jesús del Río & Calicanto & Deterioro de las torres, daño en dos tapias & $A-B$ & 2 \\
\hline 9 & Iglesia de San Andrés & Tapia pisada o adobe & Deterioro de las torres & $A-B$ & 2 \\
\hline 10 & Iglesia de La Merced & $\begin{array}{l}\text { Los muros y arcos, de calicanto. Estaba afectada } \\
\text { por sismos ocurridos en años anteriores. }\end{array}$ & Totalmente derribado el templo y su convento & A & 5 \\
\hline 11 & $\begin{array}{l}\text { Antiguo convento de La } \\
\text { Concepción }\end{array}$ & Tapia pisada, adobe o bahareque & $\begin{array}{l}\text { Semidestruido. Las monjas tuvieron que } \\
\text { trasladarse a un huerto de la congregación de } \\
\text { San Felipe Neri. }\end{array}$ & $A-B$ & 4 \\
\hline 12 & Capilla El Portal & Tapia pisada, adobe o bahareque & Semidestruida. Debía ser reconstruida. & $A-B$ & 4 \\
\hline 13 & Casa de Cabildo y cárcel & Tapia pisada, adobe o bahareque & $\begin{array}{l}\text { Quedaron arruinadas. Se sugirió trasladar a los } \\
\text { presos de la cárcel. }\end{array}$ & $A-B$ & 3 \\
\hline 14 & Carnicería & Tapia pisada, adobe o bahareque & $\begin{array}{l}\text { Fue necesario descargar el techo y el frente de } \\
\text { la casa, y con ese material se trastejó el salón } \\
\text { grande }\end{array}$ & $A-B$ & 3 \\
\hline 15 & $\begin{array}{l}\text { Colegio Jesuita, de la Compañía } \\
\text { o San Agustín }\end{array}$ & Calicanto & Arruinado. Quedó inservible. & $A-B$ & 4 \\
\hline 16 & Casa de juego de gallos & Tapia pisada, adobe o bahareque & Arruinada & $A-B$ & 3 \\
\hline 17 & Iglesia de Chapal & Tapia pisada, adobe o bahareque & Iglesia en ruinas & $A-B$ & 4 \\
\hline 18 & Iglesia de Anganoy & Tapia pisada, adobe o bahareque & Iglesia en ruinas & $A-B$ & 4 \\
\hline 19 & Iglesia de Pandiaco & Tapia pisada, adobe o bahareque & Iglesia en ruinas & $A-B$ & 4 \\
\hline $20-23$ & Barrio San Francisco & Tapia pisada, adobe o bahareque & $\begin{array}{l}\text { Tenía las casas averiadas, pero se podía habitar } \\
\text { en ellas por no estar desplomadas }\end{array}$ & $A-B$ & 2 \\
\hline
\end{tabular}




\section{Sismo del 26 de octubre de 1935}

\begin{tabular}{|c|c|c|c|c|c|}
\hline N. ${ }^{\circ}$ & Nombre & Materiales/conservación & Tipo de daño & Vul. & Grado \\
\hline 1 & Iglesia de San Sebastián & $\begin{array}{l}\text { Tapia pisada. Se encontraba averiada } \\
\text { por el sismo del } 7 \text { de agosto de } 1935 .\end{array}$ & $\begin{array}{l}\text { Las paredes laterales quedaron desniveladas y hubo grietas } \\
\text { en todos los muros. Una torre cayó y la otra quedó vencida. }\end{array}$ & $A-B$ & 3 \\
\hline 2 & Iglesia de La Merced & $\begin{array}{l}\text { Mampostería reforzada. Se encontraba } \\
\text { averiada por el sismo del } 7 \text { de agosto } \\
\text { de } 1935 \text {. }\end{array}$ & $\begin{array}{l}\text { Las paredes quedaron desniveladas. Se ampliaron las } \\
\text { grietas que había dejado el sismo del } 7 \text { de agosto de ese } \\
\text { año y se abrieron unas nuevas. }\end{array}$ & $A-C$ & 2 \\
\hline 3 & Catedral & $\begin{array}{l}\text { Mampostería reforzada. Se encontraba } \\
\text { averiada por el sismo del } 7 \text { de agosto } \\
\text { de } 1935 \text {. }\end{array}$ & $\begin{array}{l}\text { Aumentaron los daños que había causado el sismo del } 7 \text { de } \\
\text { agosto de ese año, especialmente los de la sacristía, situada } \\
\text { al costado oriental de la iglesia }\end{array}$ & $A-C$ & 2 \\
\hline 4 & Iglesia de La Panadería & Tapia pisada, adobe o bahareque & $\begin{array}{l}\text { Se cuarteó la pared que sostenía el campanario, el frontis y } \\
\text { todas las paredes quedaron desniveladas. A pesar de esto, } \\
\text { la gente asistió a misa. }\end{array}$ & $A-B$ & 3 \\
\hline $5-6$ & Barrio La Compuerta (casas) & Adobe, tapia pisada, ladrillo cocido & Casi todas las edificaciones quedaron en pésimo estado & $A-B$ & 3 \\
\hline $7-8$ & Barrio La Panadería (casa) & Adobe, tapia pisada, ladrillo cocido & $\begin{array}{l}\text { Quedó cuarteada la casa de Josefina Duarte en el barrio La } \\
\text { Panadería }\end{array}$ & $A-B$ & 3 \\
\hline $9-12$ & Barrio El Colorado (casas) & $\begin{array}{l}\text { Adobe, tapia pisada, ladrillo cocido. } \\
\text { Algunas casas se encontraban } \\
\text { averiadas por el sismo del } 7 \text { de agosto } \\
\text { de } 1935 .\end{array}$ & $\begin{array}{l}\text { Casi todas las edificaciones de este barrio quedaron en } \\
\text { pésimo estado. } \\
\text { La casa del Pbro. Pedro Martínez, que estaba siendo } \\
\text { reconstruida debido a los daños causados por el sismo del } \\
7 \text { de agosto, resultó afectada y cayó la parte alta sobre lo } \\
\text { reconstruido. }\end{array}$ & $A-B$ & 3 \\
\hline 13 & Cárcel & Adobe, tapia pisada, ladrillo cocido & El edificio quedó desnivelado, y algunas paredes, agrietadas & A-B & 3 \\
\hline 14 & $\begin{array}{l}\text { Capilla de la Virgen del Carmen } \\
\text { (Hospital San Pedro) }\end{array}$ & $\begin{array}{l}\text { Adobe, tapia pisada, ladrillo cocido. Se } \\
\text { encontraba averiada por el sismo del } 7 \\
\text { de agosto de } 1935 \text {. }\end{array}$ & $\begin{array}{l}\text { Se abrieron numerosas grietas en los arcos centrales y en } \\
\text { la cúpula }\end{array}$ & $A-B$ & 3 \\
\hline - & Casa & Adobe, tapia pisada, ladrillo cocido & Quedó destruida la casa de Felipe Obando Idrobo & $A-B$ & 5 \\
\hline
\end{tabular}

\section{Sismo del 14 de julio de 1947}

\begin{tabular}{|c|c|c|c|c|c|}
\hline N. ${ }^{\circ}$ & Nombre & Materiales/conservación & Tipo de daño & Vul. & Grado \\
\hline 1 & $\begin{array}{l}\text { Iglesia San Felipe Neri y capilla } \\
\text { de Jesús del Río }\end{array}$ & Mampostería reforzada de ladrillo & $\begin{array}{l}\text { Quedó destruida la parte superior de la torre } \\
\text { principal, y al caer se llevó consigo una pequeña } \\
\text { cúpula }\end{array}$ & $B-C$ & 3 \\
\hline 2 & Iglesia de Santiago Apóstol & Mampostería reforzada de ladrillo & $\begin{array}{l}\text { Muros agrietados y cayó una torre. Las cúpulas } \\
\text { de la iglesia quedaron considerablemente } \\
\text { desplazadas de su base. }\end{array}$ & $B-C$ & 3 \\
\hline 3 & Palacio Municipal & $\begin{array}{l}\text { Muros de tapia pisada sobre cimientos de cal y } \\
\text { ladrillo. Teja de barro cocido. }\end{array}$ & $\begin{array}{l}\text { Quedó prácticamente derruido. Sus daños fueron } \\
\text { graves. }\end{array}$ & A & 3 \\
\hline 4 & Palacio de la Gobernación & Ladrillo, tapia, piedra tallada & $\begin{array}{l}\text { Hubo una grieta grande que seguía el curso de } \\
\text { la cornisa }\end{array}$ & $A-B$ & 2 \\
\hline 5 & Plaza de mercado & $\begin{array}{l}\text { Muros de tapia pisada sobre cimientos de cal y } \\
\text { ladrillo. Teja de barro cocido }\end{array}$ & $\begin{array}{l}\text { Hubo profundas grietas y dos esquinas del } \\
\text { edificio a punto de irse a tierra. El tránsito a su } \\
\text { alrededor fue suspendido. }\end{array}$ & A & 3 \\
\hline 6 & Hospital San Pedro & Ladrillo cocido & $\begin{array}{l}\text { Graves averías que obligaban a demolerlo en } \\
\text { gran parte }\end{array}$ & B & 4 \\
\hline 7 & Palacio Nacional & Cemento armado. Constaba de seis pisos. & $\begin{array}{l}\text { Grietas en las columnas y en los techos de los } \\
\text { corredores. Ruptura de los vidrios de la fachada. } \\
\text { La Oficina de Telégrafos, que funcionaba en el 5. } \\
\text { piso, tuvo que ser trasladada. }\end{array}$ & C & 3 \\
\hline 8 & Hospital Civil & Ladrillo cocido & Grandes grietas en los muros & B & 3 \\
\hline 9 & Universidad de Nariño & $\begin{array}{l}\text { Concreto reforzado. El zócalo de los muros, de roca } \\
\text { y ladrillo cocido. Fachada de roca pulida. Cubierta } \\
\text { de teja de barro. }\end{array}$ & Se desprendieron los áticos. Quedó cuarteada. & C & 3 \\
\hline 10 & Casa de la familia Montenegro & Adobe, tapia pisada, ladrillo cocido & Quedó a punto de desplomarse & $A-B$ & 3 \\
\hline 11 & $\begin{array}{l}\text { Cementerio Central Virgen del } \\
\text { Carmen }\end{array}$ & Ladrillo cocido & $\begin{array}{l}\text { Las bóvedas quedaron destruidas, y las lápidas, } \\
\text { dispersas }\end{array}$ & A & 4 \\
\hline 12 & Escuela Industrial & - & $\begin{array}{l}\text { Prácticamente derruida. Daños de mucha } \\
\text { gravedad. }\end{array}$ & - & 4 \\
\hline 13 & Casa en la calle Angosta & Adobe, tapia pisada, ladrillo cocido & Caída de una pared & $A-B$ & 4 \\
\hline 14 & Matadero Municipal & Ladrillo cocido & $\begin{array}{l}\text { Las galerías en construcción del Matadero } \\
\text { Municipal, ubicadas en Pandiaco, sufrieron graves } \\
\text { desperfectos. Un pedazo enorme de cemento fue } \\
\text { despedido a seis metros de distancia. }\end{array}$ & B & 3 \\
\hline 15 & Edificio & Ladrillo cocido & $\begin{array}{l}\text { Un edificio de tres pisos, situado en la plazuela } \\
\text { de Santander, quedó muy afectado, y apenas } \\
\text { se sostenía en pie gracias a los puntales que le } \\
\text { pusieron los obreros. }\end{array}$ & $\mathrm{B}-\mathrm{C}$ & 4 \\
\hline $16-20$ & Casas & Adobe, tapia pisada, ladrillo cocido & $\begin{array}{l}\text { Varias casas ubicadas en la carrera } 21 \text {, entre } \\
\text { calles } 18 \text { y } 19 \text {, sufrieron daños de consideración }\end{array}$ & $A-B$ & 3 \\
\hline $21-31$ & $\begin{array}{l}\text { Barrio El Ejido, Veinte de Julio } \\
\text { y Navarrete }\end{array}$ & Adobe, tapia pisada, ladrillo cocido & $\begin{array}{l}\text { Resultaron seriamente averiadas numerosas } \\
\text { residencias de los barrios El Ejido, Veinte de Julio } \\
\text { y Navarrete }\end{array}$ & $A-B$ & 3 \\
\hline 32 & Colegio San Francisco Javier & $\begin{array}{l}\text { Arcos y columnas de mampostería. Torre central y } \\
\text { portal de piedra. }\end{array}$ & Se dañaron los muros de los lados este y oeste & B & 3 \\
\hline
\end{tabular}

